\title{
Fatigue life estimation of Francis turbines based on experimental strain measurements: Review of the actual data and future trends
}

\author{
Alexandre Presas, Yongyao Luo, Zhengwei Wang, Bao Guo \\ Department of Energy and Power Engineering, Tsinghua University, Beijing 100084, China
}

\section{ART ICLE INFO}

\section{Keywords:}

Hydropower

Renewable energy

Life estimation

Francis turbine

\begin{abstract}
A B S T R A C T
Due to the massive entrance of new renewable energies such as wind or solar, hydraulic turbines have to work far from its designed point and withstanding multiple transients, such as starts and stops, that shorten the useful life of the machine and cause fatigue damages. The present paper reviews the complex problem of fatigue in Francis turbines particularly focused on the experimental data available for static and dynamic stresses. For this purpose, many researches, which include different Francis turbines covering a wide range of design head and power, have been considered. The experimental stresses characteristics measured with strain gauges installed on the turbine runner and obtained from previous works have been analyzed for the different operating conditions and transient states occurring in the normal life of actual Francis units. The actual computational capabilities and techniques typically used to estimate such stresses have been discussed in detail. Potential future techniques to simplify complex strain measurements on the turbine runner, computational and statistical methods to estimate turbine stresses are reviewed in this paper. Finally, the relative damage of the different operating conditions and useful life estimation of the turbine, based on past strain measurements of the runner, are addressed.
\end{abstract}

\section{Introduction}

Nowadays, Hydropower plays an important role in the electricity market because hydraulic turbines permit to introduce flexibility on the electrical grid. Due to the entrance of massive renewable energy sources, such as wind or solar, not only the demand curve has an unpredictable behavior but also the generation curve. In this context, hydropower has the capacity to introduce big amounts of energy in a short period of time and regulate its output power, in order to match the generation and demand. Also, if there is a surplus of energy in the grid, reversible Francis units can be used in pumping mode as an energy storage machine. Due to its wide operating head range (from few meters up to $600 \mathrm{~m}$ [1]), Francis turbines are the most widely used turbine type. In order to match the electricity generation and demand, Francis units have to work far away from its designed operating point and hold many damaging transient conditions such as start-ups and stops. During these unfavorable conditions, high pressure fluctuations and high static stress (mean value of the stress characteristic) and dynamic stresses (fluctuation with respect the mean value) are expected, which can lead to some fatigue damages and failures. These type of damages and failures, have been reported more often during the last years as shown in multiple research papers and study cases [2-7]. The runner or impeller, which converts hydraulic into mechanical energy or vice versa, is the critical part of the unit as it receives the dynamic loads induced by the flow. Fig. 1 shows a crack found in a Francis runner caused by multiple start and stops. In order to analyze and to prevent fatigue damages, recently many research has been focused in improving the actual knowledge in all the steps that have an influence in the fatigue damage phenomena. These steps are roughly represented in Fig. 2.

On one side, the excitation characteristics and the structural parameters (masses, stiffness and damping ratios) of the unit in real operating conditions have to be determined as inputs of the dynamic problem. On the other side, the reaction of the system as a consequence of these inputs is known as the structural dynamic response (this concept is limited here to the response of the rotating structure). This response involves static and dynamic strains \& stresses. Particular in some critical points of the runner (hotspots), these stresses can be very high and with a given number of cycles, a fatigue damage or failure can occur.

There are many studies that have been focused in the main excitation types in Francis units. These excitation types are the rotor-stator-interaction or RSI, the excitations derived from the vortex rope, the Von-Karman vortex shedding and stochastic excitations at very low loads. RSI phenomena and its influence parameters have been analyzed in detail in the past [8-16]. The RSI is the main excitation type for high loads of the unit and specially for high head runners. The cavitating vortex rope and its effects on the runner have been also considered in many studies. This phenomena appears when the machine is work- 

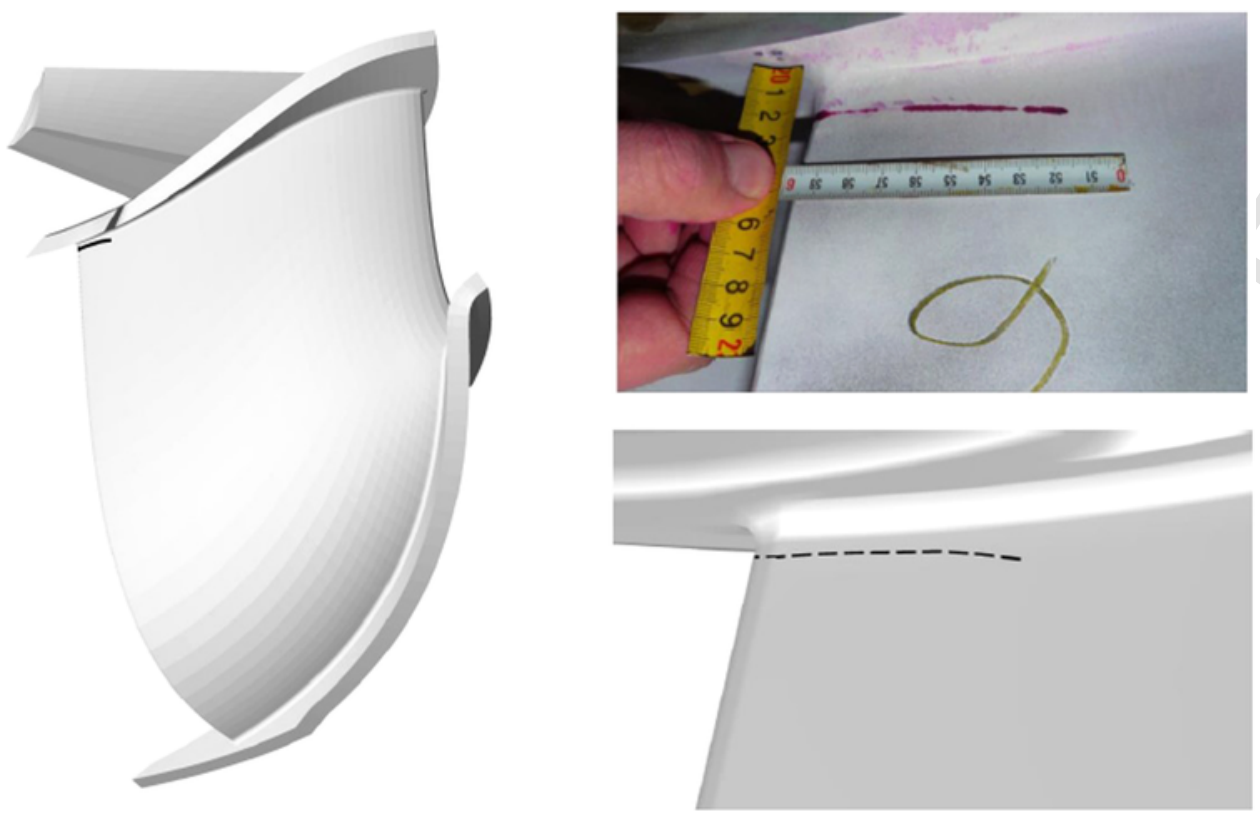

Fig. 1. Crack found in a Francis runner due to multiple starts and stops [7].

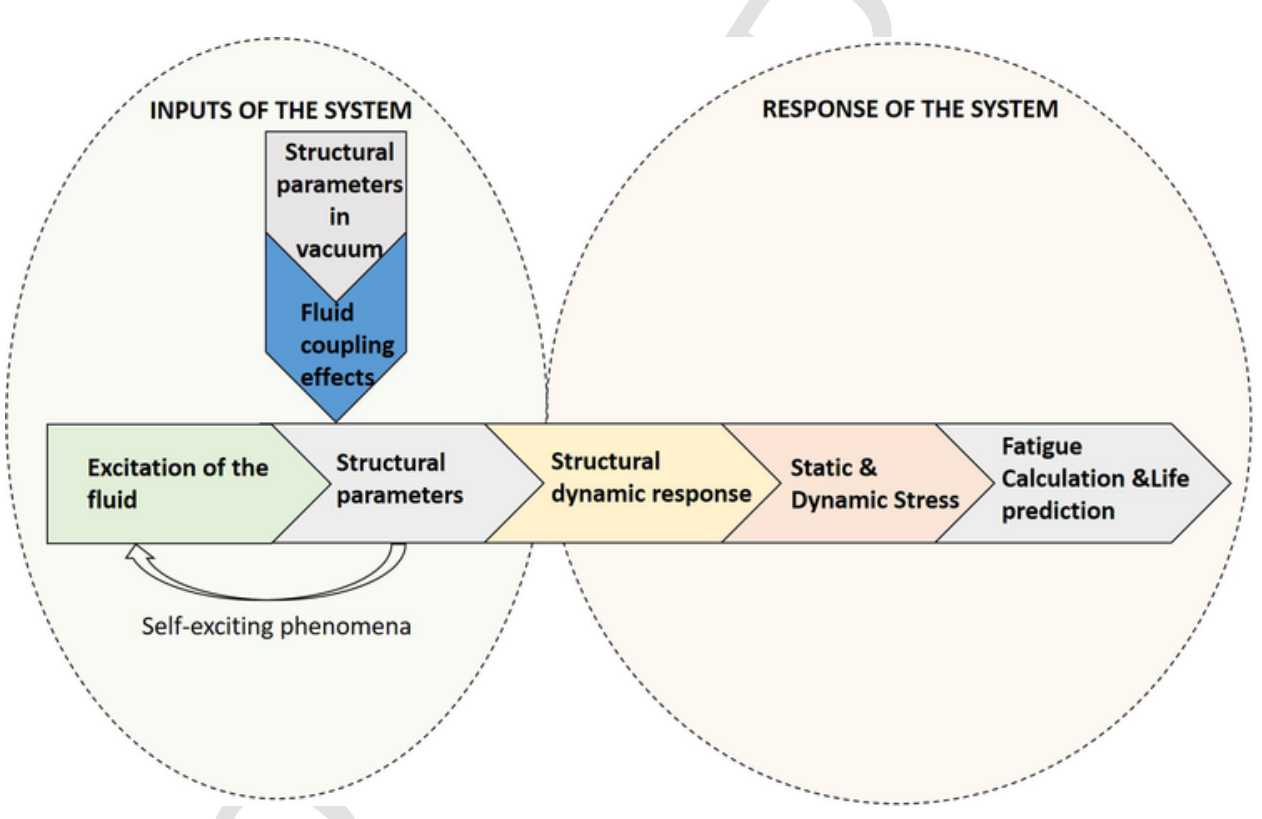

Fig. 2. Steps involving the Fatigue problem and Life assesment.

ing at part load (under best efficiency point) [17-21] and at overload conditions [22-24]. The Von-Karman vortex shedding can be especially dangerous if the frequency of the vortices coincides with one natural frequency of the blade, producing a resonance. The phenomena has been investigated and reported in isolated hydrofoils $[25,26]$ and turbine blades [17,27-30]. Finally, besides these excitations, which have a periodic characteristic, the stochastic excitations have to be considered. These are especially important at very low loads or during transients [31-34]

The effect of the fluid in the structural response of the runner, i.e. the influence of the fluid on its dynamic properties such as natural frequencies, mode shapes and damping ratios has been also deeply studied. The main phenomenon is the decrease of the natural frequencies of the runner (which is submerged and confined) due to the added mass effect, which has been extensively discussed in the last years for simplified structures [35-41] and also for real turbine runners [42-45]. The increase of the damping ratio due to standing or flowing water has been also demonstrated in many cases [38,40,46-49]. Also the influence of the rotation in disk-like structures has been determined as a very important factor [50-53]. Trivedi et al. [54] summarized all these effects in a good manner. More recently, other effects such as the coupling between acoustic and structural modes or the influence of flexible casings have been also discussed $[45,55]$.

In the recent years, the knowledge of the flow excitation characteristics and the structural response of the runner has been improved. Nevertheless, neither the excitation characteristics for all the operating points nor the structural response of the runner in operation, which is influenced by the aforementioned effects acting together, has been totally determined now. As a consequence, the static and dynamic stresses cannot be fully predicted based on this model.

In order to have more realistic fatigue life estimations, many research groups and industrial companies have been focused on the di- 
rect determination of stresses by performing experimental measurements with strain gauges. This task has a lot of technical difficulties, since the stresses have to be measured in the runner, which is submerged, rotating and withstanding high pressure fluctuations. Due to the difficulty of the installation, these tests involve long times and also high economic expenses from direct costs(technical staff, materials and shipping) and indirect costs(long periods of the machine without generation) [56].

According to Gagnon et al. in the year 2010 [57]: "Currently, there are only a few Francis turbines for which strain measurements are available". Nevertheless, by examining recent studies, it can be concluded that this situation has changed and that nowadays some papers including experimental strain measurements in the runner have been published, as will be shown in the present review. At the same time, the experimental information obtained has helped to improve the quality of the numerical models. In fact, many studies show that simulation models are capable to predict static and dynamic stresses for some operating conditions. With the evaluation of the dynamic stresses, relative fatigue damages of every operating condition have been estimated. Nevertheless, absolute fatigue life predictions are still not reliable enough as there are many uncertainties in all the steps involving this complex problem and still lack of experimental data to use advanced statistical methods.

This paper, reviews the recent developments in the life assessment of Francis turbines based on the experimental and numerical determination of stresses in the turbine runner. This topic is nowadays of relevant importance in hydraulic turbomachinery, since new conditions of the electrical market require Francis turbines to work far away from its Best Efficiency Point (BEP) and withstanding multiple transients. Due to the fact, that a reliable estimation of dynamic stresses through numerical or analytical methods is still not possible, at least in all the operating conditions, direct strain measurements on the runner are necessary and have been extensively performed during the last years. In this paper, we summarize compare and analyze together the different available stress results experimentally obtained in prototypes, which have been recently published by different researchers. Firstly, static and dynamic stresses are discussed as a function of net head and power output. For the analysis a wide number of turbine runners with different heads and operating powers has been included. Furthermore, for the static stress and dynamic stress the accuracy of the simulation models has been addressed. Then, for every typical operating condition in Francis turbines, the main conclusions of the different researches have been summarized. In order to avoid economic and environmental costs of such measurements in real turbines, new techniques and possible future trends to simplify these kind of experimental tests are also highlighted. Finally, relative damages of each operating condition based on fatigue analysis and actual reliability models are also discussed.

\section{Brief description of the flow excitations and structural dynamic response of Francis runners}

The stresses in the runner could be accurately estimated with numerical models, if the structural dynamic response would be fully known. Nevertheless, for Francis turbines this is a very complex task, as both excitation characteristic and structural parameters are affected by complex flow characteristics (Fig. 2). First, the flow excitation, especially in out of the design conditions, contains high stochastic components. Regarding the structural parameters, several fluid effects have an influence on them. Although in the recent years many of these effects have been properly analyzed and determined, there is still a long way to completely solve this problem and therefore the dynamic stress determination requires from direct experimental strain measurements on the runner. This section briefly describes the most characteristic excitations and most important influences on the structural response of Francis turbines and point out some relevant effects that have been addressed recently and that were not discussed in previous reviews dealing with this topic [54].

\subsection{Flow excitation}

Depending on the operating condition of the runner, there are different types of flow excitations. These can be roughly separated according to the following classification summarized in Table 1 . The operating conditions will be described more detailed in the Section 3 of the present paper. Regarding the flow excitation, it is worth to mention the work of Naudascher and Rockwell [58] and the work of Dörfler et al. [59] The first one gives a detailed description of the different flow-induced vibration problems in engineering and the second one carefully analyzes flow excitations in hydraulic machinery.

\subsubsection{Rotor Stator Interaction (RSI)}

It is a periodic excitation caused by the interaction between guide vanes and rotating blades. Its basic equations in terms of excited frequencies and excited mode shapes are well known. The RSI excites the turbine runner in all the operating conditions but its intensity is stronger at high loads.

\subsubsection{Rotating speed pulsations}

As real hydraulic machinery is not perfectly symmetric on the rotating and stationary parts, pressure pulsations at the rotating speed of the runner are expected. The main causes are a hydraulic unbalance of the runner and asymmetries of the casing.

\subsubsection{Vortex rope}

At part load and full load conditions, due to the fact that the flow exits the runner with some tangential component, a vortex rope can appear. The vortex rope, is usually presented in a sub-synchronous frequency range (below the rotating speed).

\subsubsection{Vortex shedding}

Occurs at the trailing edge of the blades. It can be dangerous in lock-in conditions

\subsubsection{Chaotic flow}

The flow at deep-part load and in some transient conditions is highly stochastic and therefore, its characterization is the most challenging one.

Table 1

Summary of the main excitations in Francis turbines and associated problems.

\begin{tabular}{|c|c|c|c|c|}
\hline Phenomena & Periodic/stochastic & Operating conditions & Reference studies & Associated problem reported \\
\hline Rotor Stator Interaction (RSI) & Periodic & All conditions. Stronger at high loads & {$[9,14-16,59]$} & Structural resonance runner $[51,60,61]$ \\
\hline Rotating speed pulsations & Periodic & All conditions & {$[59]$} & Undesired vibrations and failures [59] \\
\hline Vortex rope & Periodic & Part load or full load & {$[17,23,59,62,63]$} & Resonance of the hydraulic system $[22,64-66]$ \\
\hline Vortex shedding & Periodic & Mainly high loads & {$[25,27,59]$} & Lock in on the trailing edge $[27,30]$ \\
\hline Chaotic flow & Stochastic & Transients, speed no load and deep part load & {$[57,59,67,68]$} & High static and dynamic stress (see Section 5.1) \\
\hline
\end{tabular}




\subsection{Structural response of submerged runner}

As the fluid density (water) is in the same order of the structure density (stainless steel), the structural response of the runner in vacuum is totally different than the structural response of the runner in operation. This has the consequence that the modal parameters: natural frequencies, mode shapes and damping ratios will be modified with respect to those parameters calculated for the runner in vacuum. Many effects of the flow in the structural response have been separately analyzed in the past. A recent review of Trivedi and Cervantes [54] shows most of these effects. Table 2 summarizes the main flow effects on the structural response of the turbine runner which some of them have been recently published and there are not included in [54].

\subsubsection{Added mass}

The added mass effect is maybe the most relevant effect of the fluid on the structural response. Added mass effect highly decreases the natural frequencies of the submerged structure with respect to vacuum, while the mode shapes remain nearby the same.

\subsubsection{Rotation}

The relative rotation of a disk-like structure with respect to the water produces a split on the natural frequencies and mode shapes.

\subsubsection{Cavitation}

For submerged hydrofoils it has been demonstrated that with the presence of a high cavitation volume nearby, the natural frequencies of the hydrofoils increase, while damping rations may decrease.

\subsubsection{Added damping}

In still water damping ratios may be increased. Furthermore, for simple submerged plates it has been extensively shown that the damping linearly increases with the flow velocity (Hydrodynamic Damping). For real turbines, recent studies show that the damping is not linear and dependent on the flow condition (including cavitation) and mode shapes [76].

\subsubsection{Acoustic modes}

The structural natural frequencies of disk-like structures are greatly modified, when they are close to acoustic natural frequencies of the cavity and if the mode shapes are coincident.

Table 2

Main effects to be considered in the structural response of the turbine runner in operation.

\begin{tabular}{|c|c|c|}
\hline $\begin{array}{l}\text { Effect to be } \\
\text { considered }\end{array}$ & Reference studies & Main consequence \\
\hline Added mass & $\begin{array}{l}\text { Disk-like structures: } \\
{[35,37,38,50,53,69]} \\
\text { Turbine runners: } \\
{[42-44]}\end{array}$ & Reduction of the natural frequencies \\
\hline $\begin{array}{r}\text { Rotation } \\
\text { effects }\end{array}$ & $\begin{array}{l}\text { Analytical [15], } \\
\text { Experimental [50] }\end{array}$ & $\begin{array}{l}\text { Split of the natural frequencies and } \\
\text { mode shapes become rotating }\end{array}$ \\
\hline $\begin{array}{l}\text { Cavitation } \\
\text { influence }\end{array}$ & {$[70-74]$} & $\begin{array}{l}\text { Decrease added mass and increase } \\
\text { structural natural frequencies }\end{array}$ \\
\hline $\begin{array}{l}\text { Added } \\
\text { damping }\end{array}$ & $\begin{array}{l}\text { Still Fluid: }[38,40,46] \\
\text { Hydrodynamic } \\
\text { damping: }[54,75]\end{array}$ & Damping ratios increase \\
\hline $\begin{array}{r}\text { Acoustic } \\
\text { modes }\end{array}$ & {$[45]$} & $\begin{array}{l}\text { Reduction of the natural frequency for } \\
\text { structural-acoustic coupling }\end{array}$ \\
\hline $\begin{array}{l}\text { Non-rigid } \\
\text { walls }\end{array}$ & {$[55]$} & $\begin{array}{l}\text { Possible increase of the natural } \\
\text { frequencies }\end{array}$ \\
\hline
\end{tabular}

\subsubsection{Non-rigid surfaces}

It is known that for structures getting closer to rigid surfaces, the added mass increases and the natural frequencies decreases. Nevertheless, for flexible covers, this assumption may not be true and can be the opposite one (i.e. increasing frequencies with decreasing gap).

\section{Stress measurement from the runner}

This section will discuss the main conclusions obtained from several experimental and numerical studies investigating the stress on the runner for all the operating conditions. During the last decade, the amount of experimental and numerical studies considering the stress on the runner has greatly increased. New electrical grid scenario demands the work of Francis units in out of design conditions and therefore, turbine manufacturers, owners and research groups have performed expensive experimental campaigns and time consuming numerical simulations in order to investigate this topic.

Consequently, during this period experimental techniques have been improved [61,77] and the numerical models are more reliable nowadays $[7,61,78-81]$. Nevertheless, as pointed in some of these references for certain operating conditions (deep part load conditions and speed no load), where the excitation is mainly stochastic, simulation models still need to be refined. Furthermore, in cases where the flow induces an excitation frequency close to one natural frequency of the runner, the accuracy of the simulation models may be compromised due to the incomplete knowledge of the modal properties, such as natural frequencies and damping ratios (see comments on Section 2).

\subsection{Strain gauge installation and stress hotspots in Francis units}

In order to properly estimate the fatigue life of a runner, strain gauges are located in "hotspots" or locations with maximum stress. These locations are usually determined according to simulation models or previous experimental knowledge $[61,77,81,82]$. For a wide range of specific speeds (which determine the Francis unit design [1]), these hotspots are normally located at the trailing edge of the blades in the joints blade-crown or blade-band [61,81-83] (excepting reversible Francis units, which will be discussed below). Strain gauges are usually placed on the suction side and pressure side of the blades. Fig. 3 shows the typical location of strain gauges in Francis units for three different runners. As seen in this figure, strain gauges are located on the trailing edge close to the crown or to the band joint.

The orientation of the strain gauge is usually selected in the direction of the principal stress [83]. Strain gauges and wires need to be cover by an epoxy component protection in order to withstand the high mechanical solicitations during the transients and operating conditions of the machine. Usually, the voltage source and amplifier for the strain gauges are inside the cone of the Runner (in a waterproof environment). Then, the signals can be recorded with an on-board acquisition system [82] or transmitted from a rotating sender to a stationary receiver $[61,83]$, with the use of two antennas. These antennas can be located at the top of the shaft or in the draft tube.

Some studies have discussed the uncertainties of strain gauges measurements when they are installed in Francis units [84]. As seen in Fig. 4, part of this uncertainty comes from deviations in the location and orientation of the strain gauge during the installation. The integration effect comes from the fact that the strain gauge integrates the strains under its active grid, which is not a single point. The last source of error comes when the strain gauge is welded to a support platform to help its gluing to the surface of the measured structure.

The location of "hot-spots" with maximum stress for pump-turbine runners or reversible Francis units is different according to some researches $[2,13,60]$. This is due to the different geometry of pump-tur- 

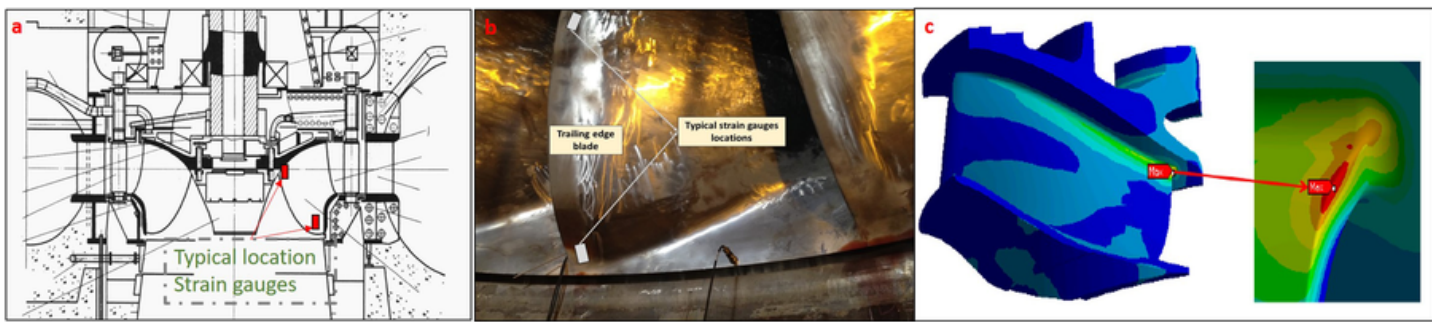

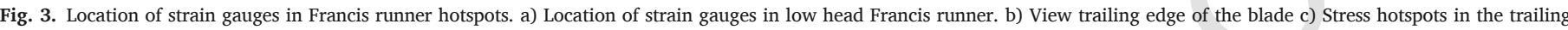
edge of a Francis runner [77].

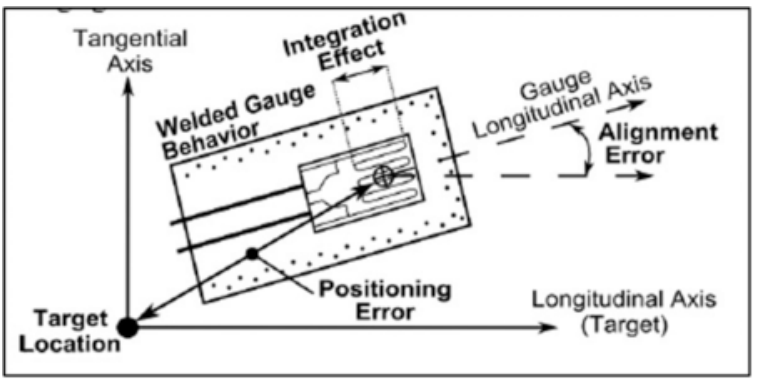

Fig. 4. Main source of error when locating strain gauges [84].

bine runners, with less blades and more curved. For this kind of units the stress hotspot is usually located in the crown, close to the joint with the leading edge of the blade as shown in Fig. 5. This point perfectly corresponds to the damage found in [2].

\subsection{Turbine runners analyzed}

In this review we analyze together the different data available regarding static and dynamic stresses measured in Francis turbines prototypes. The data is taken from different recent researches. Although this data is still limited and mainly provided by turbine manufacturers in a normalized way, some interesting conclusions can be obtained after analyzing the different turbine runners of Table 3 , which cover a wide range of net head (from low to high head) and operating power. This table, shows the main characteristics of the runners used for this purpose. The nomenclature R1-R13 will be used in the text and figures to refer to these turbine runners.

\subsection{Static stresses characteristic. Influence of head and load}

The total stress measured in the hotspot is the superposition of a mean value (static stress) and a dynamic component (dynamic stress). Both components can be clearly appreciated in Fig. 6 for the whole op-

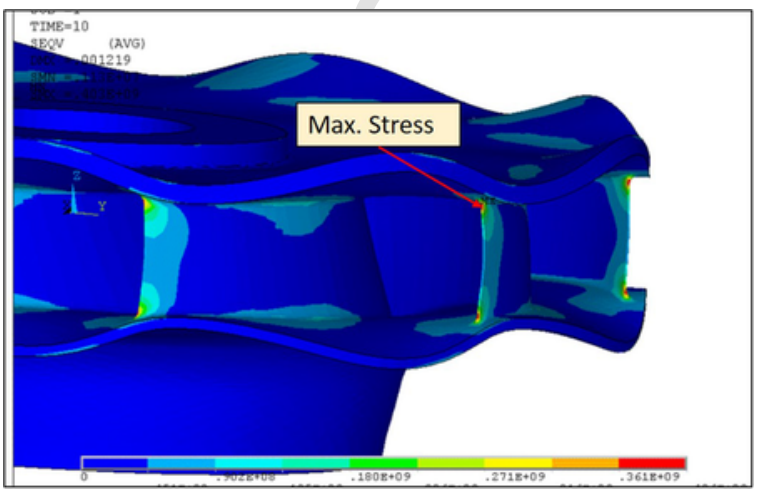

Fig. 5. Maximum stress in a pump-turbine runner prototype.
Table 3

Main characteristics of the turbine runners used for the analysis of the present review.

\begin{tabular}{|c|c|c|c|c|}
\hline $\begin{array}{l}\text { Name of the } \\
\text { runner in the } \\
\text { present Study }\end{array}$ & $\begin{array}{l}\text { Power } \\
\text { (MW) }\end{array}$ & $\begin{array}{l}\text { Head } \\
(\mathrm{m})\end{array}$ & $\begin{array}{l}\text { Specific } \\
\text { speed }\end{array}$ & $\begin{array}{l}\text { Comment and extra } \\
\text { information }\end{array}$ \\
\hline & & & $\mathbf{n}_{\mathrm{q}}[61]$ & \\
\hline R1 [81] & & $\begin{array}{l}377 \\
\text { (High } \\
\text { head) }\end{array}$ & $27^{\mathrm{a}}$ & $\begin{array}{l}28 \text { guide vanes, } 17 \\
\text { blades, } 375 \mathrm{rpm}\end{array}$ \\
\hline R2 [61] & - & $\begin{array}{l}\text { Medium } \\
\text { Head }\end{array}$ & - & $\begin{array}{l}24 \text { guide vanes, } 15 \\
\text { blades, } 150 \mathrm{rpm}\end{array}$ \\
\hline R3 [61] & - & $\begin{array}{l}107 \\
\text { (Medium } \\
\text { Head) }^{\mathrm{a}}\end{array}$ & 60 & - \\
\hline R4 [61] & - & $\begin{array}{l}168 \\
\text { (Medium } \\
\text { Head) }^{\mathrm{a}}\end{array}$ & 45 & - \\
\hline R5 [61] & - & $\begin{array}{l}616 \\
(\text { High } \\
\text { head) }\end{array}$ & 20 & - \\
\hline R6 [82] & $150 \mathrm{MW}$ & $\begin{array}{l}72.5 \\
\text { (Low } \\
\text { Head) }\end{array}$ & 76 & $\begin{array}{l}20 \text { guide vanes, } 15 \\
\text { blades, } 125 \mathrm{rpm}, 4.9 \mathrm{~m} \\
\text { diameter. Unit: } \\
\text { Stornorrfors }\end{array}$ \\
\hline R7 [77] & - & - & - & - \\
\hline R8 [77] & $200-400$ & $\begin{array}{l}80 \text { (Low } \\
\text { Head) }\end{array}$ & 73 & $\begin{array}{l}\text { Designed for one } \\
\text { operating point }\end{array}$ \\
\hline R9 [77] & $>400$ & $\begin{array}{l}80 \text { (Low } \\
\text { Head) }\end{array}$ & 73 & Wide operation \\
\hline R10 [77] & $200-400$ & $\begin{array}{l}170 \\
\text { (Medium } \\
\text { Head) }^{\mathrm{a}}\end{array}$ & 45 & Widest operation \\
\hline R11 [77] & $0-200$ & $\begin{array}{l}500 \\
(\text { High } \\
\text { Head) }\end{array}$ & 22 & $\begin{array}{l}\text { Designed for one } \\
\text { operating point }\end{array}$ \\
\hline R12 [68] & - & $\begin{array}{l}\text { Low } \\
\text { Head }\end{array}$ & - & $\begin{array}{l}\text { Designed for one } \\
\text { operating point }\end{array}$ \\
\hline R13 [68] & - & $\begin{array}{l}\text { Low } \\
\text { Head }\end{array}$ & - & Wide operation \\
\hline
\end{tabular}

a Approximated Head or Specific speed, estimated based on the relation between Specific Speed and Head given in [1] with $r=0.95$ (correlation coefficient).

erating range of a Francis unit. As seen in this figure, both static and dynamic stresses highly depend on the operating condition of the unit.

These conditions, which correspond to the turbine quadrant mode (IEC60193 second edition, Table 11 \& Fig. 114), can be roughly separated as follows:

Start-up: Transient condition until the machine reach the speed no load condition

Speed no load: The unit is running at nominal speed (IEC 41 third edition, sub-clause 2.3.4.10) and waiting to be connected to the generator. Deep part load: The unit is generating at a very low power. The flow is highly stochastic.

Load change: During the transition from one steady operating condition to another and in order to generate more or less power depending the operator desire, the flow rate passing through the machine is modified by moving the wicket gates. Some references [85] state that this transi- 


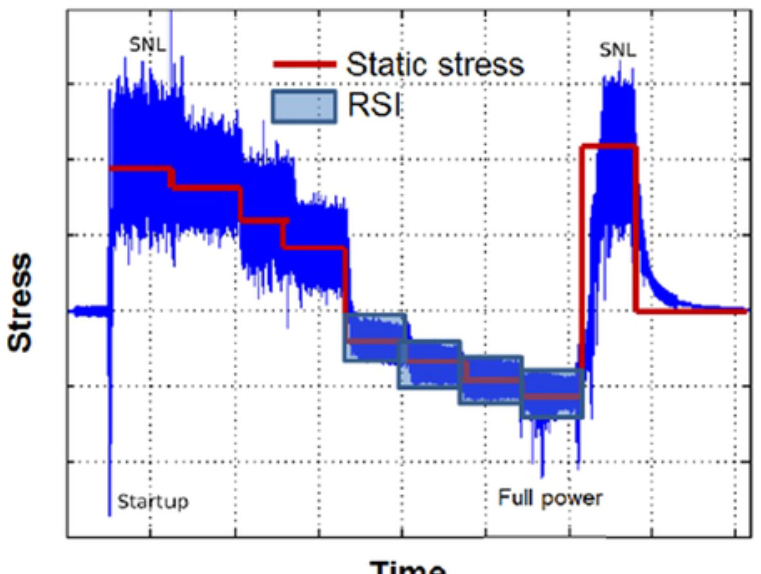

Time

Fig. 6. Static and dynamic stress characteristic for the full operating range of a Francis turbine [77].

tion can be neglected in terms of fatigue analysis and do not consider it $[68,81]$, while some reviews show the importance of take it into account [86].

-Part load: The unit is generating power below its best efficiency zone. This zone is usually characterized by the well-known part-load vortex rope

-Full load: This includes the Best Efficiency Point (BEP) and therefore the flow is generally smooth and the dynamic stresses are smaller (excepting the RSI in high head units and the full load instability)

Shut down: The machine goes to a low load and then it is disconnected from the generator. At the same time the wicket gates are progressively closed and the unit deaccelerates

-Load rejection: This is not a normal event in the runner life (it is also not shown in Fig. 6). It happens when the machine rejects a load and suddenly loss its resistance torque in the generator. This transient is characterized by a sudden acceleration of the unit over the nominal speed (IEC 41 third edition, sub-clause 2.3.4.13) and a progressive deceleration when the wicket gates are almost closed.
According to many studies, the static stresses in the hotspots have been accurately predicted with the actual numerical simulation models $[61,68,77,81,82]$. Usually the numerical models consider the pressure field from the CFD simulation and introduce it into the FEM model, with the centrifugal forces due to the rotation of the runner and gravity loads $[61,81]$. The one-way method should be accurate enough for the static stress calculations as the deformation of the structure is relatively small and should not generally affect the flow field [80]. The FEA model can make good predictions if proper boundary conditions are defined $[80,81]$. It should be also noted, that although the calculated trends of static stress can be very consistent with the experimental data, deviations still exist for some operating conditions. This is because the accuracy of static stress calculations strongly depends on pressure loads transmitted from the CFD. For some unstable conditions, such as the startup, SNL, load rejection or the deep part-load, accurate predictions for the pressure loads can be very difficult due to its stochastic nature and so will the static stress.

The data of static stresses as function of the power is available for the turbines R1, R2, R6 and R7 on Table 1. Fig. 7 shows the evolution of the static stress on the crown and on the band for the different turbines. All of them show a decreasing trend of the mean stress with increasing power on the crown (Fig. 7a) and an increasing mean stress on the band (Fig. 7b). Fig. 8 shows the discrepancy between experimental and numerical simulation for R1 and R2 in crown and band. Especially on the band there is a trend to increase the error between numerical and experimental data for increasing power of the machine. Finally, comparing numerical and experimental static stress allows to evaluate the quality of the simulation model for the more challenging prediction of dynamic stresses.

\subsection{Dynamic stresses for the full operating range}

\subsubsection{Influence of the head and load}

Although the dynamic stress characteristics will depend, for every particular runner, on the operating point, there are some generic trends that can be stated from the review of recent experimental studies, for instance $[61,77,81,82,87]$.
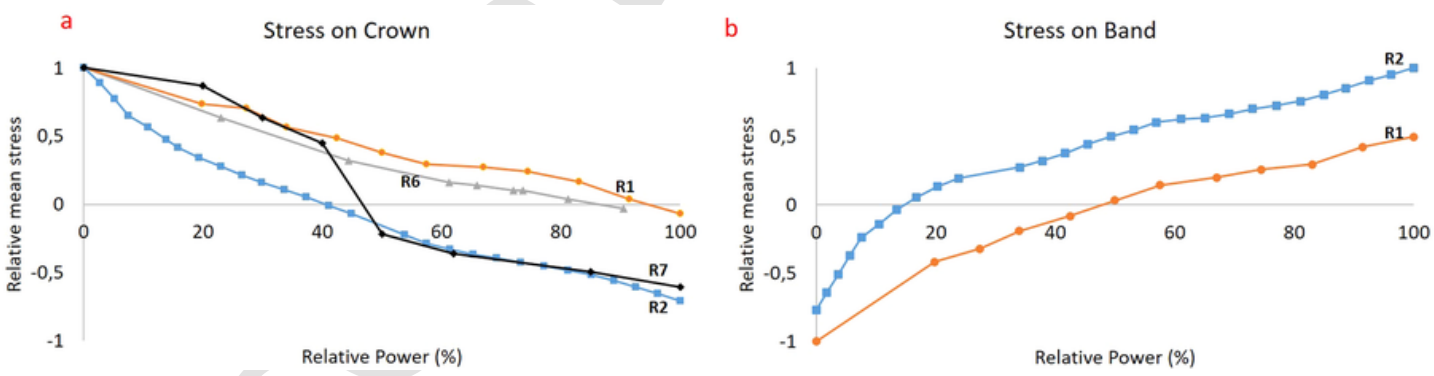

Fig. 7. Static stress vs Power for the runners on Table 1. a) Crown, b) Band.
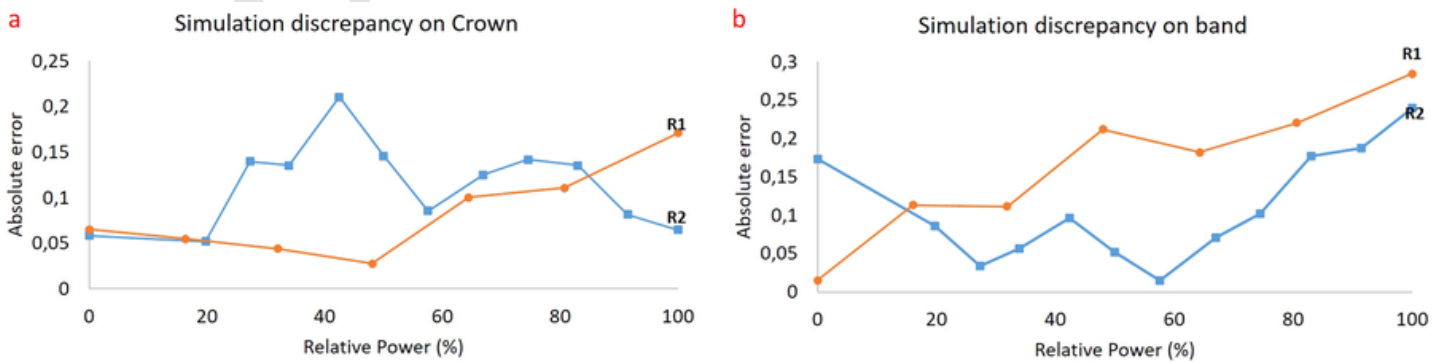

Fig. 8. Discrepancy of simulation-experimentation vs Power for the runners on Table 1. a) Crown, b) Band. 
The first interesting conclusion is about the relative dominance of the RSI characteristic on the dynamic stress. In [61] the relative importance of the RSI is presented as a function of the specific speed. In that study, a correlation between specific speed and RSI relevance is obtained using the data of different Francis Turbines working at rated condition (relative high load). Due to the existing relationship between specific speed and net head, the regression used in [1] (correlation coefficient $r=0.95$ ) is considered here to obtain a relationship between the RSI contribution on the dynamic stress and the net Head of the runner (Fig. 9). As seen in this figure, approximately below $70 \mathrm{~m}$ of net head, the contribution of the RSI on the dynamic stress at rated conditions is very low (about $5 \%$ ). Above $70 \mathrm{~m}$ and until $170 \mathrm{~m}$, this contribution greatly changes from about $5-80 \%$ of the dynamic stress. For higher net heads this contribution remains nearly constant.

Regarding mid to high head Francis runners, where the induced RSI stress is important (see Fig. 9) it is interesting to show how this RSI induced stress varies across the operating power. This is shown in Fig. 10 for the turbine runner R1 (head of $377 \mathrm{~m}$ ). It can be appreciated that at about $50 \%$ of the operating power the contribution of the RSI suddenly increases and it is maintained on a high level until the full load. In such conditions the relative velocity at the inlet of the runner is high and so is the contribution of the RSI on the dynamic stress. Therefore, for low specific speed Francis runners (High head and low flow rate), both the low loads and the high loads have to be analyzed in detail. In terms of numerical prediction of the dynamic stresses, due to the deterministic nature of the excitation, good agreement between experimental and numerical results have been found, at least if the RSI excited frequencies are well separated from a natural frequency of the runner, as will be shown in Section 3.4.5.

For high specific speed Francis runners (Low Head and High Flow rate), the most unfavorable conditions are the deep part load conditions and speed no load as seen in Fig. 11, for low head runners. For speed no load and deep part load, the nature of the excitation is mainly stochastic. As a consequence, the predictions of pressure loads and dynamic stresses with numerical models have to include statistical parameters, making the problem more challenging. In the following, we discuss and review the different operating points in detail.

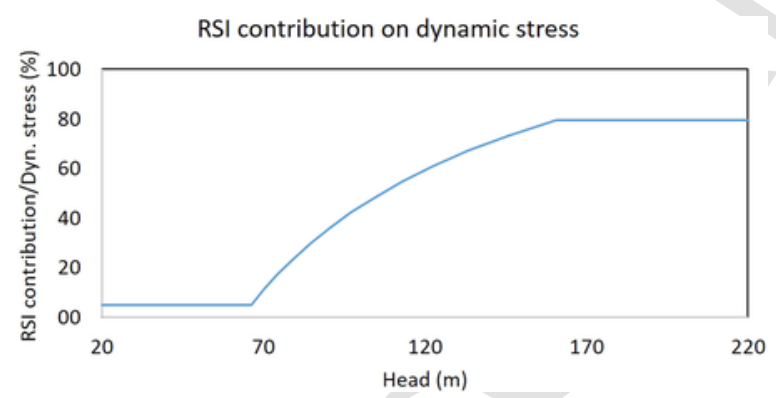

Fig. 9. Relative importance of the RSI in the dynamic stress vs Net Head. Rated conditions.

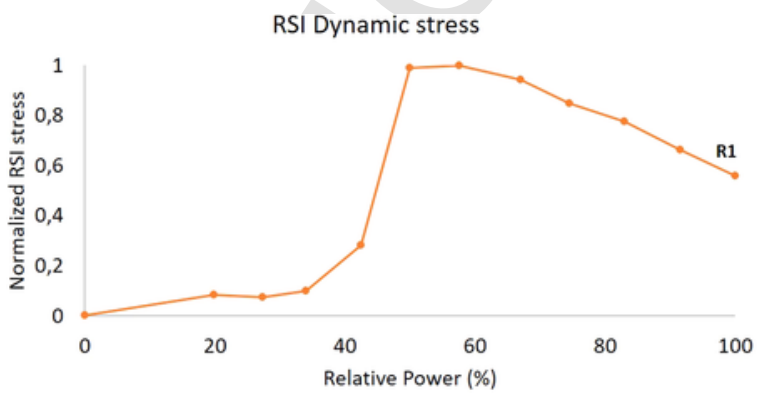

Fig. 10. Relative importance of the RSI in the dynamic stress vs Power for high head Francis turbine.

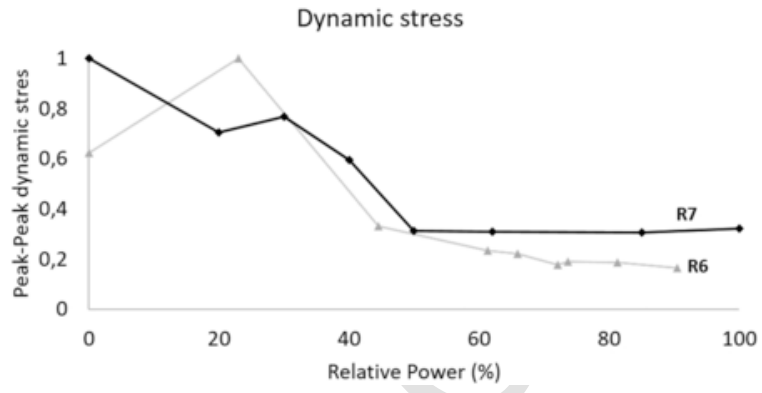

Fig. 11. Evolution of the dynamic stress for low head Francis turbine runners.

\subsubsection{Start up}

The acceleration of the unit until its nominal speed is one of the critical operating conditions $[57,68,85,88]$. Due to its damaging characteristics, in the last years, a lot of research has been performed in the optimization of the start-up process, which can decrease notably the static and dynamic stresses during this transient phenomena $[57,68,85,86,89]$. The main optimization possible consists of the adjustment of the wicket gates opening law, which can be modified by the plant operator (with some restrictions regulated by IEC61362 [85]) $[57,68,85]$. Some possibilities also include the admission of air during the acceleration, which seems to reduce the dynamic stresses [85].

Gagnon et al. [85] compared four different start-ups schemes trying to reduce the maximum stress on the runner and the pressure fluctuation on the hydraulic circuit. In this experiment, the wicket gate opening in $\%$ and rate change $\% / s$ used during the process were varied. An interesting conclusion of that study was that low rate change (therefore longer time for the acceleration) minimize the maximum stress, although this has two drawbacks. Firstly, the time to synchronization with the power grid will be longer, which contradicts the grid requirements (mentioned in Section 1). Secondly, some hydraulic instabilities during the transient will have more time to be developed and for the same reason some resonances of the runner could be more amplified [60].

An example of the effects of an optimized start-up can be seen in Fig. 12. The main idea of many researches reviewed $[57,68,85,90]$, which have experimentally demonstrated to reduce the dynamic stress, is to make a smoother and longer acceleration time.

The numerical prediction of the induced stresses in the start-up is a complex topic, due to the transient nature of the phenomena. Nicole et al. [91] show a very complete study of the CFD configurations during start-up. Four different simulation models were analyzed to establish the most important components affecting the simulations. The rotating speed and guide vane opening usually keep changing during the start-up process. Therefore, the dynamic mesh generation (remesh process) has to be carefully controlled, since some elements can become extremely distorted. Once the pressure loads are obtained, the dynamic stresses can be calculated with the FEA model. In that study, the mean values of the stress could be compared to the experimental ones as shown in Fig. 13.

Finally, another very damaging situation which has been less discussed in the recent years, is the excitation of a resonance of the runner during the start-up. Although the time will be very short, since the excitation frequency (RSI) is continuously increasing (runner is continuously accelerating), the amplitudes can be very high if a resonance occur. Therefore, with a high number of start-ups, the effects on the runner are not negligible. This issue has been investigated in the past specially for high-head pump-turbines $[13,15,16]$, concluding that it was may the cause of some critical failures [13,14]

More recently, $\mathrm{He}$ et al. [60] investigated numerically and experimentally a possible resonance during start-up (for a reversible Francis 


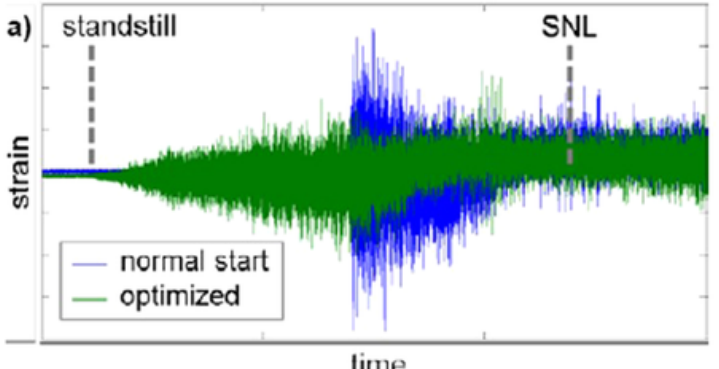

$\operatorname{lime}$

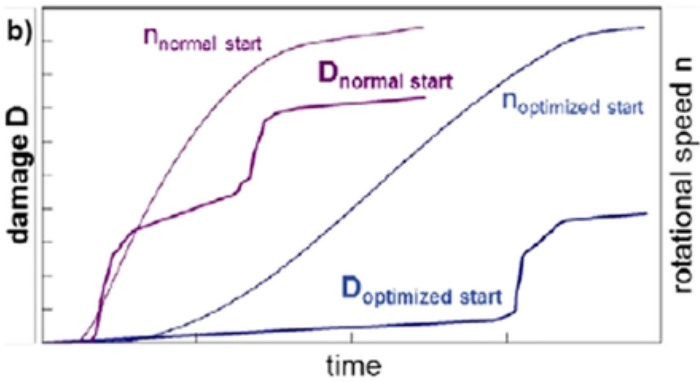

time

Fig. 12. Effects of an optimized start-up [68].
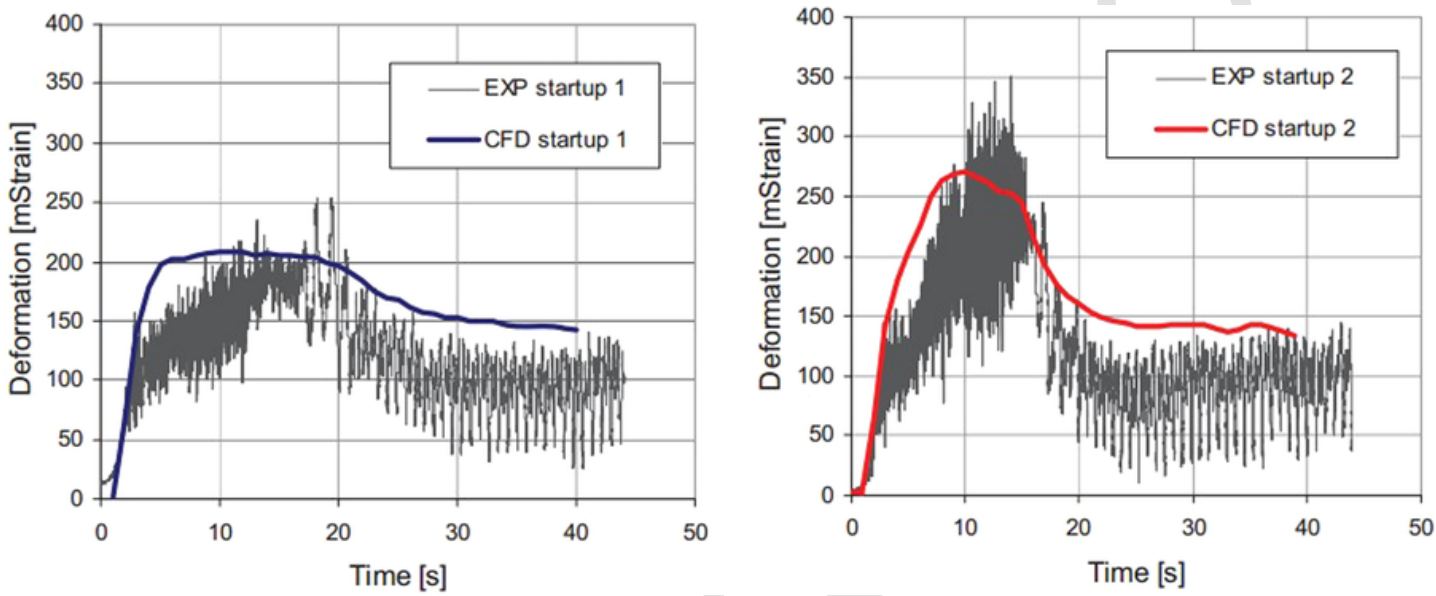

Fig. 13. Stress comparisons between the computational and experimental results during two different startup [91].

unit), showing that in this case, the dynamic stress amplitudes were extremely increased. For an accurate estimation of the natural frequencies of the runner, the added mass effects have to be considered. Therefore, the clearance flow, which greatly contributes to this effect [38] was considered in that study. The pressure loads obtained with CFD were transferred to the acoustic-structural FEA model. Using a one way simulation scheme, dynamic stresses during the resonance could be predicted with good accuracy (same level of stress and slight differences in the resonance point estimation), as shown in Fig. 14.

\subsubsection{Speed no load \& deep part load}

In this situation, the runner is rotating at nominal speed but without load in the generator (or almost no load in deep part load condition). This implies, that all the potential energy of water has to be dissipated producing high turbulences. This condition is also one of the most damaging condition due to its high amplitude stresses $[32,68,87,92,93]$. The excitations at speed no load are mainly stochas-

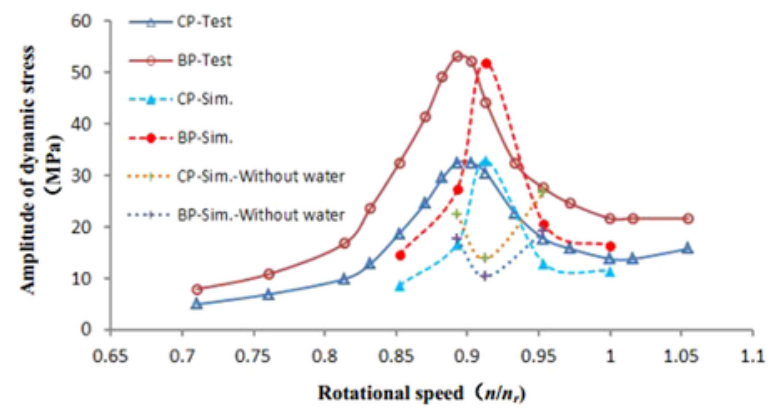

CP - Crown Point, BP - Band Point, Sim. - Simulation

Fig. 14. Dynamic stress on the runner in a resonance during start-up. Comparison experimental and simulation [60]. tic $[61,68,77,94]$, although the RSI excites the runner also [95,96]. As seen in Fig. 15, from the measured signal of a strain gauge, in the first part of the spectrum the stochastic nature (not well defined frequency) dominates the response.

The prediction of the dynamic stresses during this operating condition by means of numerical simulation models is very complex and is still not a solved topic $[68,92,94]$. Accurate predictions of the stochastic pressure loads become the main obstacle for successfully assessing the dynamic stresses. According to many authors [32,34,68,92], SAS turbulence model would bring out more of the stochastic characteristics of the loads than the classical $\mathrm{k}-\varepsilon$ turbulence model adopted with RANS. Therefore, for speed no load conditions and deep part load, where the loads are mainly stochastic, RANS models are not good enough. Morissette et al. [92] showed that although the low frequency part of the spectrum can be fairly good predicted by using numerical models, high frequency components cannot be well captured (Fig. 15). He also suggested, that this could be improved in the future with more refined meshes, smaller time steps, better turbulence models and cavi-

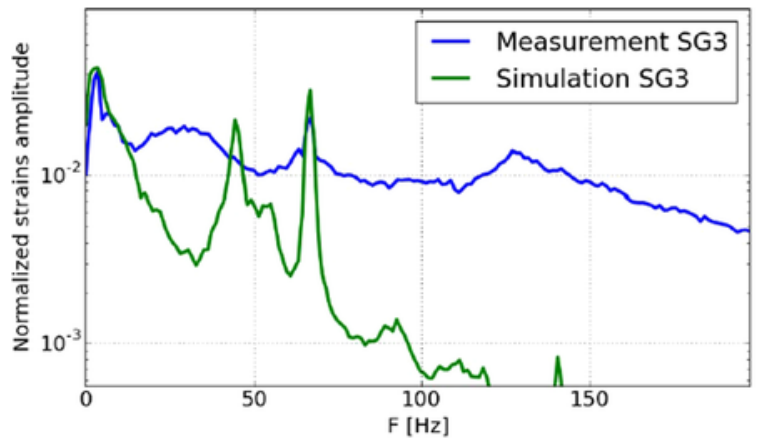

Fig. 15. Stochastic nature of the runner stress at speed no load [92]. 
tation consideration. C. Trivedi in a more recent study shows that the prediction of the RSI components and harmonics in this operating condition can be well estimated by means of compressible LES simulations [97].

According to Mende et al. [34], although the shape of the frequency spectrum of the SAS is roughly good, amplitudes can be better predicted with LES model if the simulated time is large enough. Therefore, although LES requires a very high computational cost nowadays, this model is a promising way for the future $[34,68]$.

\subsubsection{Part load}

By increasing the load, generally a precessing vortex rope appears $[61,64,68,98,99]$, with a well-defined precession frequency below the rotating speed. For some particular operating points an hydraulic resonance can occur, producing high power swings [63]. This condition cannot be accepted as a possible operating condition of the turbine, due to the high power swing and therefore it will not be considered here. Beside this condition, it can be concluded that the dynamic stresses on the runner due to the part load vortex rope are generally much smaller than the dynamic stresses induced during speed no load conditions $[77,87,93,100]$.

Particularly, according to the experiments of Bouajila et al. [93], where several model tests were instrumented with strain gauges, in the operating point where the vortex rope has its strongest intensity (possible part load resonance [63]), the stresses are two order of magnitude less than the deep part load condition. Even so, the relative damage is one order of magnitude greater than the BEP (Fig. 16). Similar conclusion obtained Duparchy et al. [100] when analyzing an hydroacoustic resonance at part load; while the dynamic pressure clearly increases, the increase of the dynamic stresses on the runner is not so relevant.

The dynamic stresses in a part load condition (with the presence of the vortex rope) have been predicted with numerical simulation models recently [68,101]. The estimation of the pressure loads with the CFD model is more complex in this case, since cavitation phenomenon needs to be considered. In such case, the election of the cavitation model has to be evaluated and a sensitivity analysis for the different models may be performed [101]. As the vortex rope is a low frequency phenomenon, more simulated time needs to be considered which implies longer computational time. Furthermore, in order to capture the RSI phenomena small time steps are necessary. Fig. 17 shows the experimental and simulation results of dynamic strain at part-load conditions under the influence of the precessing vortex rope. In this case, the low frequency components of the signal were accurately predicted, while the high components (such as RSI) could not be captured as the time step was not small enough [101].

\subsubsection{Full load conditions}

Generally speaking, this zone is the softest zone in terms of pressure fluctuations and dynamic stresses. The BEP is considered to be inside this operating condition. In this condition and specially for high head Francis runners, the attention has to be paid on the RSI, as seen in Figs. 9 and 10.

In this situation and due to the periodic characteristic of the excitation, simulation models show that dynamic stresses can be predicted with good accuracy $[61,68,77,81,82,87,102]$. Seidel [61] and Guilaume [102] give complete descriptions for calculations under full load conditions. Using the Fast Fourier Transform to process the pressure signal obtained from the CFD, the amplitude and phase can be obtained directly for given frequencies. The most relevant frequency can then be used for a harmonic analysis on the structural FEM.

Fig. 18 shows the experimental results against the numerical results for different monitoring points (strain gauges) located in four different runners (R1, R3-R5). The numerical results are obtained as explained above. Note that R1, R4 and R5 are high head runners and R3 a mid-head runner and therefore all of them exhibit a strong RSI at full load conditions (Figs. 9 and 10). Therefore, the main excitation is deterministic and good linear correlations can be observed in Fig. 18. It can be stated that numerical simulations can be used to predict dynamic stresses of relative high head runners at high loads, where the RSI dominant is.

The situation, where one of the RSI frequencies is close to one natural frequencies of the runner is less discussed $[2,61,81]$ and can also drastically reduce the runner life due to the high dynamic stress amplitudes [2]. In this case, for a reliable prediction of the stresses, an accurate knowledge of the runner natural frequency and damping ratio is fundamental. In the analyzed case by Seidel et al. in [61], it is mentioned that the excited frequency is far from the natural frequency and therefore the dynamic stresses can be well predicted without exactly knowing the damping ratio. Nevertheless, in the analyzed case by $\mathrm{X}$. Huang et al. the damping ratio had to be calibrated with experimental results in order to accurately predict the dynamic stresses with simulation models [81].

The particular case of a lock-in condition in the trailing edge of the blades is not usual and has been reported in few cases. If it occurs, it is

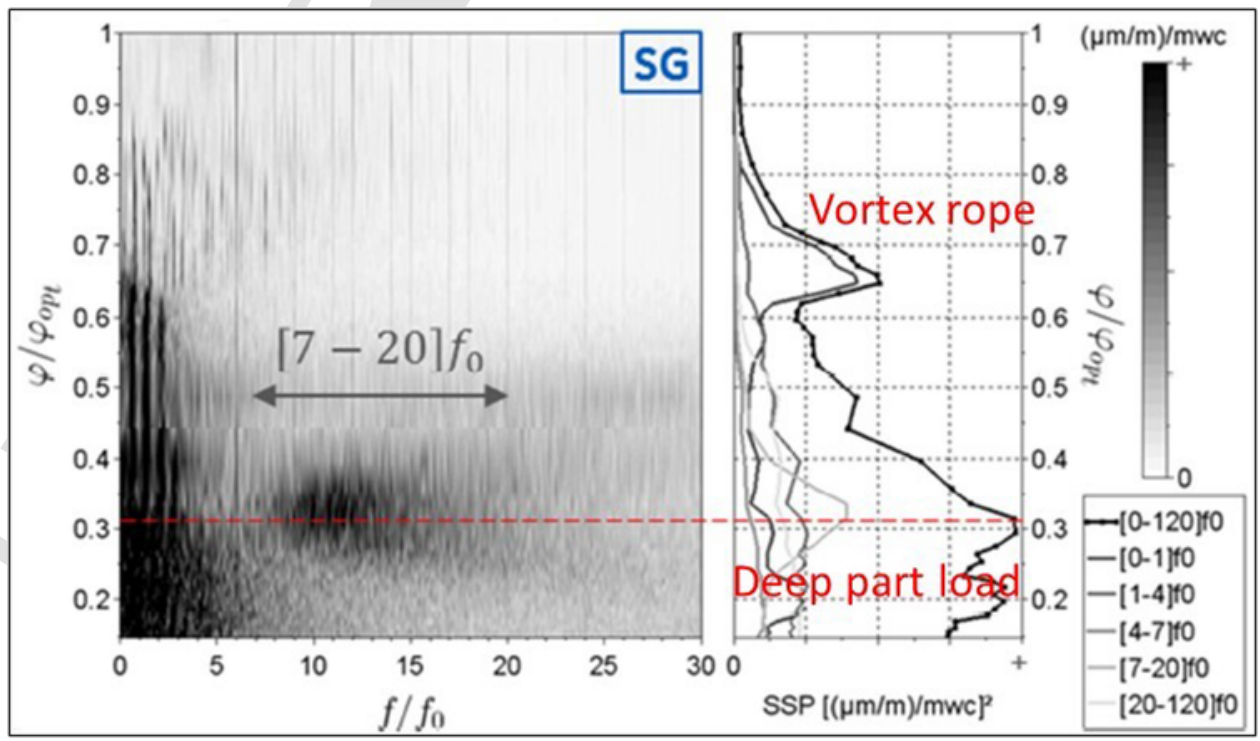

Fig. 16. Comparison dynamic stress amplitudes at part load (vortex rope) and Deep part load [93] 


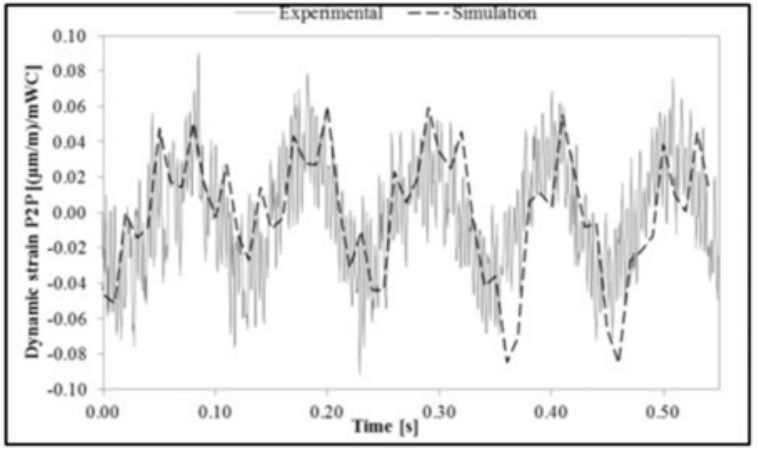

Fig. 17. Comparisons of dynamic stress at part load condition. Experimental and numerical [101].

expected to happen for high loads, when the relative velocity in the blade passage is high and the vortex-shedding frequency (which depends on the velocity according to the Strouhal number) coincides with one natural frequency of the blade (lock-in condition). Although it is an infrequent case in Francis turbines, its effects can be very serious and they can damage the trailing edges of the blades in a few hours of work as reported in [30].

The case of a full load instability is not generally considered, because it is not an acceptable stable operating condition, due to the high power swings $[22,103]$.

\subsubsection{Shut down and load rejection}

For normal stop procedure usually the unit is going to a low power and then disconnected from the generator. At the same time the wicket gates start to close so that the rotating speed is reduced under certain value, where the unit can be mechanically braked. Compared to the transient of the start-up, shut-down is usually neglected, since its damages are not so important [85]. Nevertheless, according to that study, its effects on the runner, regarding useful life, are not negligible and similar as for the start, an optimized procedure could contribute in the minimization of these damages.

More critical is the case of a load rejection for relative high loads. In this case the unit is accelerated to a runaway speed, that can be almost two times the rotating speed [1], before the unit starts to deaccelerate. In this case a structural resonance may occur due to the increasing excitation frequency of the RSI, producing also high dynamic stresses. Damaging effects can be also important if the governor sequence is not properly adjusted [85]. The same study suggests, that the use of an air admission during the load rejection could reduce the dynamic stresses on the runner. In spite of this potential damaging effects, load rejections are not considered as a normal event in the life of the Francis units.

According to the authors' knowledge, there are no papers predicting dynamic stresses during load rejection by means of computational simulation. The most probably reason is the difficulty for an accurate prediction of the pressure loads. Nevertheless, some papers have been

Dynamic stress full load

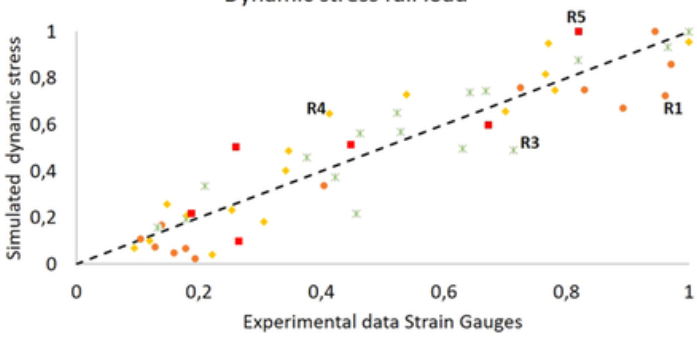

found, where this transient condition has been computationally addressed and pressure fluctuations have been estimated [104-106]. Efforts have been conducted to consider the elastic water hammer. Detailed simulation methods have been discussed by Cherny [106]. In that study Unsteady RANS model was used. The water hammer was considered at the turbine inlet and outlet using a 1D-3D coupling method. Although pressure fluctuations were calculated by means of CFD, no comparison with experimental results were reported.

\section{Future techniques and perspectives to estimate dynamic stresses on the runner}

Dynamic stress measurements involves high direct costs(equipment, staff) and indirect costs (loss of energy production, environmental) [31,107]. The total time for such measurements can take around one month [56]. Such measurements have helped to improve the knowledge of dynamic stresses in Francis turbines and therefore life assessments are more reliable now. Nevertheless, it is necessary to find more economic, faster and reliable methods to predict dynamic stresses. This chapter review some methods that have already started to be used and also future possibilities based on a technology review.

\subsection{Indirect methods}

These methods consist of simplifying as much as possible the on-site measurements tests. Instead of using sensors on the runner, which implies much longer periods of time for the installation, the basic idea is to estimate the same information with sensors installed on the stationary frame (vibration sensors \& pressure sensors) or strain gauges on the rotating shaft $[68,90]$, whose installation can take few hours or a couple of days.

Diagne et al. [90] used shaft torsion measurement for this purpose. According to that study, shaft-torsion measurements are highly correlated to stress on the runner and this type of measurements are much cheaper (usually strain gauges on the shaft can be placed in one day without dewatering the runner). They performed a measuring campaign including both type of sensors (stress on the runner \& torsion shaft). Briefly described, first the spike noise due to electrical phenomena was removed from the signals with a 3D phase space method [108]. After that, the ARMAX model (auto regressive polynomial model) [109] was used to predict the dynamic stresses on the runner based on the dynamic stresses on the shaft. It was shown, for different start-ups sequences, that the RMS error between the predicted and the measured value was around $25 \%$ for a second order of polynomials model. This algorithm was tested for the start-up sequence but not for the rest of the operating conditions.

\subsection{Other experimental techniques for stress determination}

\subsubsection{Optical fiber}

The basic idea of the optical fiber, is that one fiber is a "sensing nerve" in all of its extension. When the fiber is attached to a surface, it

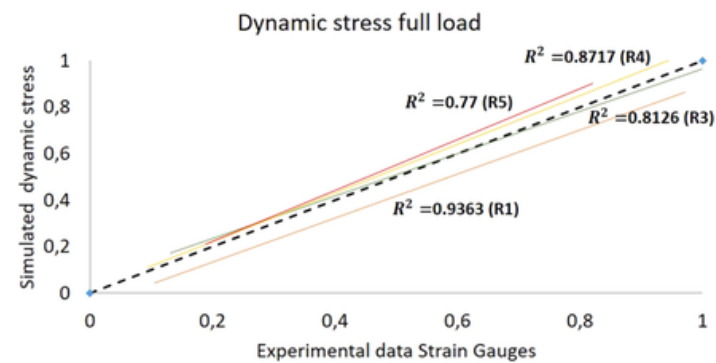

Fig. 18. Dynamic stress comparison at full-load conditions. Experimental and numerical simulations at crown and band. 
can be used to measure strain/stress in the whole line/surface covered. Therefore, it is acting as a multiple sensor system. In the last years, optical fiber has been used for strain measurement in several applications [110-113]. Although, most of them consider the static strain, there are also some studies considering the dynamic strain measurement [112], which is also of relevant interest when measuring a turbine blade. The use of such fiber in a turbine blade would reduce the cost of installing many strain gauges and avoid the mechanical difficulty of fastening heavy powering systems on the rotating frame (optical fiber are intrinsically passive sensors). Ideally, the stress could be measured in much more points than with the strain gauges. Some strain gauge manufacturers actually offer these sensors as substitution of classical gauges [114]. The main drawback of these kind of sensors, at the present, is the gauge factor and the spatial resolution. Nevertheless, with the improvement of measurement techniques with optical fibers, the spatial resolution is now in the order of mm instead of sub-meters [113]. Fig. 19 shows a possible installation of a single optical fiber (multi-sensing) in a turbine blade. Such shape of the optical fiber, which is a similar one to that one used by Minardo et al. [115] minimizes the curvature of the fiber and could permit to measure the stresses in much more points than a discrete number of strain gauges.

\subsection{Computational methods}

In the previous section, the prediction capabilities of computational methods have been discussed in detail for every operating point. Nevertheless, all of the presented studies use experimental results to validate the computational methods. The natural trend should be to progressively substitute experimental measurements and have reliable predictions of dynamic stresses with only computational methods.

From the fluid side, as shown in the references given in Section 3.4, CFD methods have proven to have good prediction capabilities for the pressure characteristics especially at full load conditions, when the RSI dominates. Nevertheless, for deep part-load, speed no load and tran-

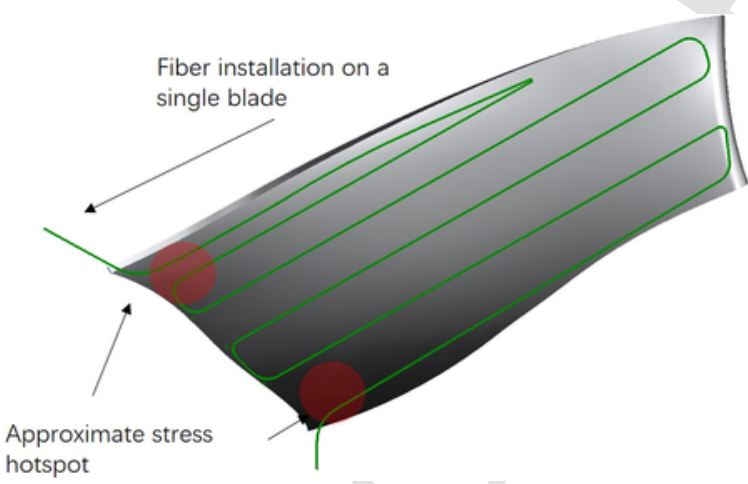

Fig. 19. Possible installation of a single optical fiber (multi-sensing) in a turbine blade. sients there are intrinsic difficulties due to the stochastic nature of the loads.

Recent studies [97] have shown the capability of LES model to approach the pressure fluctuations of the RSI components in these complex condition. Nevertheless, the prediction of stochastic fluctuations is still challenging. Finally, to include water hammer effects in the 3D model for all the fluid domain including the turbine, would improve the predictions in some transients such as load rejections

From the structural FEM, more accurate estimation of the natural frequencies and damping ratios will improve the reliability of stress predictions for the cases when the characteristic frequency of the pressure load is close to a natural frequency of the runner. For this reason, the main effects commented in Section 2 should be included in the structural model.

\subsection{Statistical methods}

The reliable extrapolation of measured data is one of the key points in the case of stress in hydraulic turbines. Although extreme value theory and neural networks have been used for the extrapolation of this kind of data in other applications [116-119], in the particular case of hydraulic turbines usually one record is available [31], due to the aforementioned difficulties when performing dynamic stress measurements on the runner.

Gagnon et al. [31] proposed a non-stationary stochastic method to extrapolate signals acquired during one start up for a reliable life assessment. It was concluded that long-term reliable service histories of transients could be obtained with just one measurement. With the same purpose Poirer et al. [107] used cyclostationary models [120] in order to predict dynamic loads in steady state conditions. As in the previous study, the necessity to estimate reliable long term signals (with deterministic and stochastic components) with just one short measured signal was pointed out (Fig. 20).

The aforementioned studies show that by the use of an appropriate signal processing method, short experimental signals can be extrapolated for a more reliable life assessment of the turbine. Furthermore, with the increasing number of data available in the upcoming years, these and other statistical methods combined could be used for a reliable extrapolation of such signals, minimizing as much as possible the number of experimental tests necessary.

\section{Life expectancy according to stress measurements}

The static and dynamic stresses in the hotspots are the departure point for fatigue life assessment methods. Based on this information, a relative or absolute life prediction can be performed.

The relative life prediction, has been performed by many researchers recently and it has the aim to make a comparison within the different operating conditions. This comparison is useful for machine operators, because they can evaluate the relative cost of using the machine in some very damaging conditions.

To define an absolute failure criterion (or an absolute value for the reliability of the runner) is much more complicated and has to include

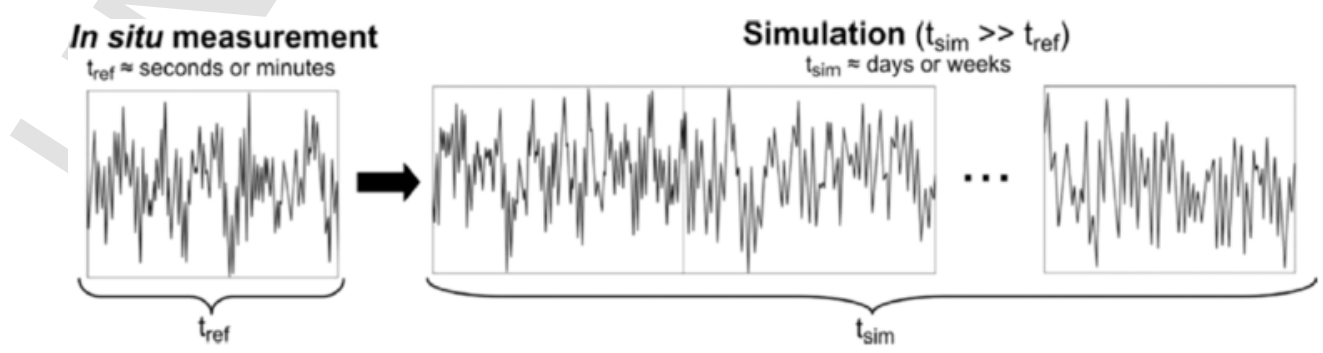

Fig. 20. Extrapolation of one single signal of order $10^{\circ} \mathrm{min}$ to $10^{7} \mathrm{~min}$. [107]. 
statistic models. Recently, extensively work has been also performed trying to define the reliability of a hydraulic runner (Gagnon et al.), given the stress measurements and the high cycle fatigue behavior of the material.

\subsection{Relative damage of the operating conditions}

Using the stress measurements, the relative damage of every operating condition can be easily obtained by classical fatigue methods. This type of study has been recently made by the respective research groups of some of the main hydraulic turbines manufacturers $[7,68,77,82,83,93,94,101,121]$.

Stress measurements (with the same time length) acquired for different operating conditions are considered. Using the well-known rainflow algorithm [122], the dynamic stress time signal is transformed in cumulated number of cycles vs stress. Fig. 21 shows the typical diagram obtained after applying this algorithm on the stress signals of a Francis turbine at speed no load and part load condition.

The use of the rainflow algorithm permits to establish, the number of stress cycles for every amplitude level (Eq. (1))

$\sigma_{i}=f\left(n_{i}\right)$

Where $\sigma_{i}$ is the stress level $i$ and $n_{i}$ the number of cycles with that level of stress. Then the Minner's rule [123] is applied to combine all the rainflow stress characteristic (Eq. (2)).

$\sum_{i=1}^{k} \frac{n_{i}}{N_{i}}=C$, with $N_{i}=g\left(\sigma_{i}\right)($ S.NCurve $)$

$C$ defines the cumulative damage. $N_{i}$ is the number of cycles necessary to produce a failure at the level $\sigma_{i}$. $N_{i}$ can be taken from the S.N curve of the material tested. According to the theory, when the value $C=1$, a failure should occur. The Rainflow curves generated with few seconds or minutes of signals, will give a $C$ value which will be much smaller than 1 , since it is not expected to have a failure in such short time. Nevertheless, the relative comparison of $C$ for the different operating conditions tested can be used to estimate the relative damage.

Fig. 22 shows the relative damage as function of the operating condition (operating power) for different runners of Table 3 . For all of the runners the most damaging position is between the speed no load (0\%) and deep part load (until 25\%). As an example, if the relative damage number is 1000 , this means that if the runner work for one hour at this condition, the accumulated damage will be the same as $1000 \mathrm{~h}$ working in its best condition (relative damage 1). Note that the best condition is at $75-90 \%$ of the power for all the runners considered.

As seen in the same figure, for the turbine runners R6, R8, R9, R12 and R13, which are low head runners the relative damage after part load conditions (around $20 \%$ of the active power) decreases fast as the RSI does not contribute at higher loads. On the opposite side, for R11, which is the highest head runner in this comparison, the RSI is impor-

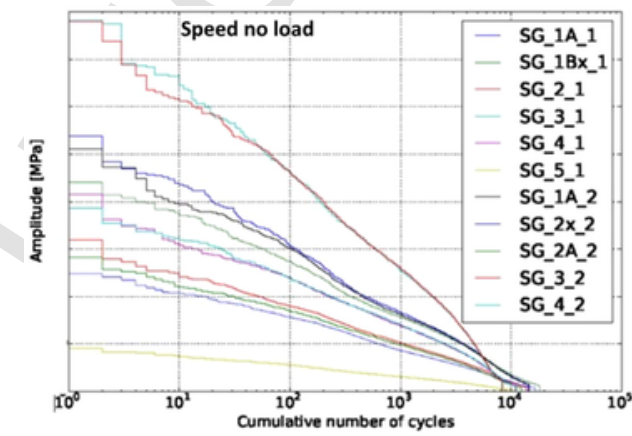

tant and therefore it exhibits a higher relative damage for high loads. Nevertheless, at Speed No Load, the relative damage is less important for this runner.

The runners R9, R10 and R13 are turbine runners designed for a wide range of operation according to Table 3 . Comparing the relative damage of these turbines at low loads and until the optimal point (relative power $25-75 \%$ ), these runners exhibit the best performance. Furthermore, R13 exhibits also a good performance at high loads. Therefore, these runners are better to be used for regulation purposes working at part loads.

These type of graphs may be useful for the turbine operators, to balance the life cost of using the machine at part load or deep part load conditions and the economic benefit of doing it. They can also be useful for turbine manufacturers in order to design runners adapted to a specific life plan or Design Reference Mission [82,94]

\subsection{Failure criteria and reliability}

Although, the Minner's rule can give some interesting conclusions when different operating conditions are compared, it may not be used as an "absolute" prediction for the fatigue life in Francis turbines. This rule was initially developed to more simplified cases and its formulation is deterministic [124]. Furthermore, from the S-N diagram it is not possible to estimate the residual life given an actual state if the accumulated damage is not known. Therefore, more complex failure criteria and reliability index of the runners have been adopted by operators of Francis units. The departure assumptions to adopt the ideas mentioned in the following paragraphs are:

1. The risk of a catastrophic failure in a Francis runner, which compromise the safety of the powerplant, is limited. The main concerns are from reparation costs and downtime period (economical) [125-128]

2. In order to reduce repair costs, a crack has to be repaired as soon as it is detected but the interval between inspections should be maximized to reduce the downtime of the unit [125-127,129]

Furthermore, according to the Linear Elastic Fracture Mechanics, the growth of a crack (or flaw) during the first part of its life is slow and defined by the Low Cycle Fatigue (LCF), i.e. only high amplitude stresses (usually associated to low frequency) contribute to the slow propagation of the crack. The influence of high cycle fatigue (HCF), which has normally smaller amplitudes and higher frequencies, is not seen in this first stage, as shown in Fig. 23. Nevertheless, after a point in time, which is known as HCF onset, the HCF loads lead to a rapid propagation of the crack (shown in Fig. 23 as the step line).

Taking into account this evolution of the defect size; if the time between inspections is too short (before the HCF onset point), no crack would be clearly detected because of its small size, although the HCF onset point may be close. Nevertheless, if the inspection occurs after the HCF onset, the crack length may be considerable large (according

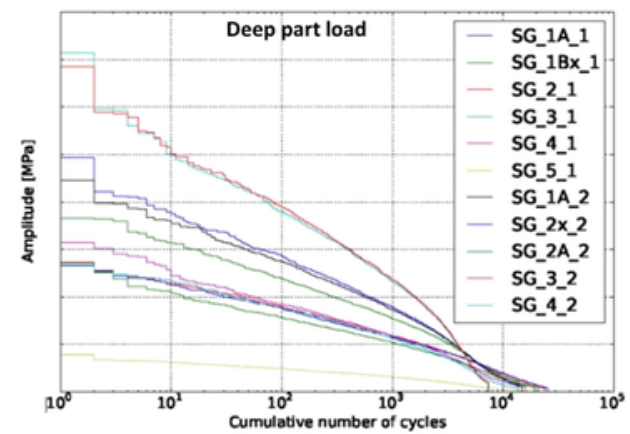

Fig. 21. Rainflow algorithm applied to strain measurement data in a Francis turbine [82]. 


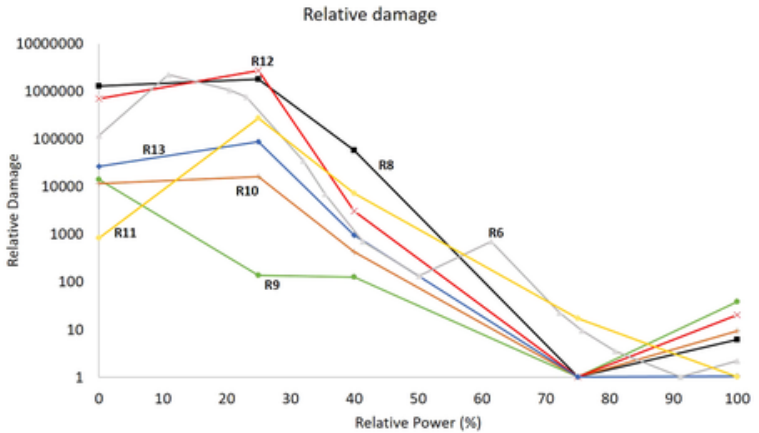

Fig. 22. Relative damage of different turbine runners as a function of the operating condition.

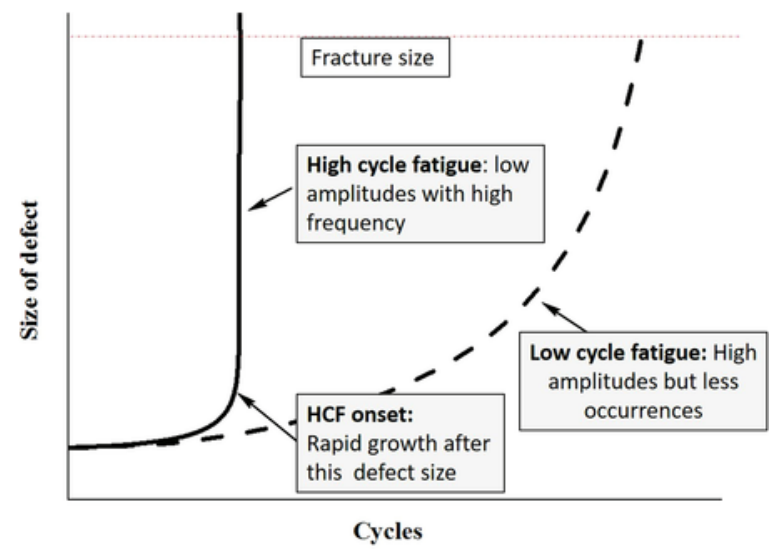

Fig. 23. Evolution of a crack length (LCF only) and LCF + HCF.

to the rapid grow after HCF onset) and therefore repair costs will be very high.

Therefore, according to the work made by Gagnon et al. [125-129] the failure criteria is defined as the HCF onset and the reliability of the runner is defined as the probability of not exceeding this point. In order to define the state limit, where the HCF onset occurs, the Kitagawa-Takahashi diagram [130] with the correction proposed by El Haddad et al. [131] was used in those studies. The limits define the thresholds below which HCF does not contribute to a rapid growth of the crack. Using this diagram, the uncertainties of every parameter and a probabilistic model, the reliability of the runner, based on experimental measurements, could be defined. Probabilistic models have to be used, as uncertainties appear in the determination of the stress level, the size defect, the HCF onset and the $\sigma_{0}$ (Fig. 24). In this context, the reliability is defined as the probability of not exceeding the limits defined in this diagram considering all the possible uncertainties [125-129].

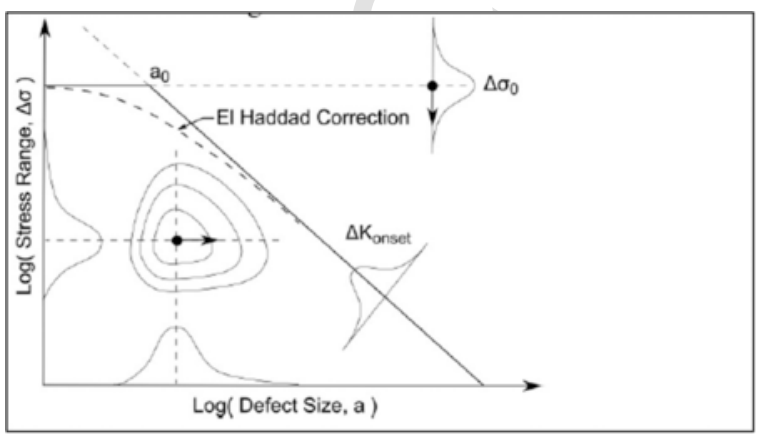

Fig. 24. Kitagawa-Takahashi diagram with the variables with uncertainties introduced by Gagnon et al. [125].

\section{Summary}

Fatigue life assessment in hydraulic turbines and particularly in Francis turbines is of relevant interest nowadays. Due to the massive entrance of intermittent renewable energy sources, Francis turbines have to work far away from design conditions and withstand multiple transients, that shorten their useful life and cause fatigue damages. The review of several studies related to fatigue and structural problems in hydraulic turbines leads to the following main conclusions:

- The flow excitation characteristics and structural parameters of Francis turbines in operation are only partially understood and cannot be completely simulated with numerical models. Therefore, in order to address the fatigue problem, it is still necessary to determine stresses with complex experimental measurements on the turbine runner.

- Static stresses on the hotspots show a similar trend with the relative power for different runners. Simulation results obtained with actual computational methods can approximate relatively well the experimental results.

- Start-up transient, speed no load and deep part load conditions show high static and dynamic stresses. The main component of such stresses is stochastic and therefore the estimation of them with computational methods is still challenging. At higher loads, where periodic phenomena (such as RSI) dominate, dynamic stresses determined with numerical models approach well the experimental ones.

- There are potential experimental techniques (indirect measurements, optical fiber) which could simplify and maybe improve actual experimental measurements with strain gauges on the runner. Also computational and statistical methods will improve as the existing experimental data (reference data for comparison) will become larger.

- Relative damages of different operating conditions can be estimated with simple fatigue models. Different studies agree that start-up, speed no load and deep part load are the most harming ones for the turbine. Nevertheless, for an accurate useful life estimation more complex fatigue models using probabilistic approaches have to be used.

\section{Acknowledgement}

The authors want to express its gratitude to all the authors, worldwide experts in this topic, who have kindly allowed us to reproduce his/her illustrative figures enhancing the quality of the present work. Special thanks to Ulrich Seidel, Xingxing Huang, Martin Gagnon, Christine Monette, Jean-François Morissette, Jonathan Nicolle, Florian Duparchy, A. Lyutov and Sofien Bouajila.

The authors thank the National Natural Science Foundation of China (No. 2018M631466, No. 51439002, No. 51779122) for supporting the present work.

\section{References}

[1] F. De Siervo, F. De Leva, Modern trends in selecting and designing Francis turbines, Water Power Dam Constr 28 (1976) 28-35.

[2] E. Egusquiza, C. Valero, X. Huang, E. Jou, A. Guardo, C. Rodriguez, Failure investigation of a large pump-turbine runner, Eng Fail Anal 23 (2012) 27-34.

[3] U. Dorji, R. Ghomashchi, Hydro turbine failure mechanisms: an overview, Eng Fail Anal 44 (2014) 136-147.

[4] X. Liu, Y. Luo, Z. Wang, A review on fatigue damage mechanism in hydro turbines, Renew Sustain Energy Rev 54 (2016) 1-14.

[5] Frunzăverde D, Muntean S, Mărginean G, Campian V, Marşavina L, Terzi R. et al. Failure analysis of a Francis turbine runner. In: IOP conference series: earth and environmental science: IOP Publishing; 2010, p. 012115.

[6] D. Momčilović, Z. Odanović, R. Mitrović, I. Atanasovska, T. Vuherer, Failure analysis of hydraulic turbine shaft, Eng Fail Anal 20 (2012) 54-66.

[7] Lyutov A, Kryukov A, Cherny S, Chirkov D, Salienko A, Skorospelov V. et al., Modelling of a Francis turbine runner fatigue failure process caused by fluid-structure interaction. In: IOP conference series: earth and environmental science, 49; 2016, p. 072012. 
[8] Z. Zuo, S. Liu, Y. Sun, Y. Wu, Pressure fluctuations in the vaneless space of High-head pump-turbines-a review, Renew Sustain Energy Rev 41 (2015) 965-974.

[9] Nicolet C, Ruchonnet N, Avellan F. One-dimensional modeling of rotor stator interaction in Francis pump-turbine. In: Proceedings of the 23rd IAHR symposium Yokohama; 2006

[10] Zobeiri A, Kueny J-L, Farhat M, Avellan F. Pump-turbine rotor-stator interactions in generating mode: pressure fluctuation in distributor channel. In: Proceedings of the 23rd IAHR symposium - Yokohama; 2006.

[11] C.G. Rodriguez, E. Egusquiza, I.F. Santos, Frequencies in the vibration induced by the rotor stator interaction in a centrifugal pump turbine, J Fluids Eng Trans ASME 129 (2007) 1428-1435.

[12] Nicolet C, Ruchonnet N, Alligné S, Koutnik J, Avellan F. Hydroacoustic simulation of rotor-stator interaction in resonance conditions in Francis pump-turbine. In: IOP conference series: earth and environmental science: IOP publishing; 2010. p. 012005

[13] H. Tanaka, Vibration behavior and dynamic stress of runners of very high head reversible pump-turbines, Int J Fluid Mach Syst 4 (2011) 289-306.

[14] H. Ohashi, Case study of pump failure due to rotor-stator interaction, Int J Rotating Mach 1 (1994) 53-60.

[15] Kubota Y, Ohashi H. A study on the natural frequencies of hydraulic pumps. In: Proceedings of the 1st ASME joint international conference on nuclear engineering; 1991, p. 589-93.

[16] Y. Kubota, T. Susuki, H. Tomita, T. Nagafuji, T. Okamura, Vibration of rotating bladed disc excited by stationary distributed forces, Bull JSME 26 (1985) 1952-1957.

[17] Ruprecht A, Helmrich T, Aschenbrenner T, Scherer T. Simulation of vortex rope in a turbine draft tube. In: Proceedings of the 22nd IAHR symposium on hydraulic machinery and systems; 2002, p. 9-12.

[18] A.I. Bosioc, R. Susan-Resiga, S. Muntean, C. Tanasa, Unsteady pressure analysis of a swirling flow with vortex rope and axial water injection in a discharge cone, J Fluids Eng 134 (081104) (2012) 11.

[19] D. Jošt, A. Lipej, Numerical prediction of non-cavitating and cavitating vortex rope in a Francis turbine draft tube, Stroj Vestn-J Mech Eng 57 (2011) 445-456.

[20] Koutnik J, Krüger K, Pochyly F, Rudolf P, Haban V. On cavitating vortex rope form stability during Francis turbine part load operation. In: IAHR international meeting of the workgroup on cavitation and dynamic problems in hydraulic machinery and systems, Barcelona, Spain; 2006.

[21] A. Favrel, A. Müller, C. Landry, J. Gomes, K. Yamamoto, F. Avellan, Dynamics of the precessing vortex rope and its interaction with the system at Francis turbines part load operating conditions, J Phys: Conf Ser (2017) 813.

[22] A. Müller, A. Favrel, C. Landry, F. Avellan, Fluid-structure interaction mechanisms leading to dangerous power swings in Francis turbines at full load, J Fluids Struct 69 (2017) 56-71.

[23] Müller A, Favrel A, Landry C, Yamamoto K, Avellan F. On the physical mechanisms governing self-excited pressure surge in Francis turbines. IOP conference series: earth and environmental science: IOP Publishing; 2014, p. 032034.

[24] A. Müller, M. Dreyer, N. Andreini, F. Avellan, Draft tube discharge fluctuation during self-sustained pressure surge: fluorescent particle image velocimetry in two-phase flow, Exp Fluids 54 (2013) 1514.

[25] P. Ausoni, M. Farhat, X. Escaler, E. Egusquiza, F. Avellan, Cavitation influence on von Kármán vortex shedding and induced hydrofoil vibrations, J Fluids Eng 129 (2007) 966-973.

[26] B. Ji, X. Luo, Y. Wu, X. Peng, Y. Duan, Numerical analysis of unsteady cavitating turbulent flow and shedding horse-shoe vortex structure around a twisted hydrofoil, Int J Multiph Flow 51 (2013) 33-43.

[27] X. Escaler, E. Egusquiza, M. Farhat, F. Avellan, M. Coussirat, Detection of cavitation in hydraulic turbines, Mech Syst Signal Process 20 (2006) 983-1007.

[28] M. Sick, W. Michler, T. Weiss, H. Keck, Recent developments in the dynamic analysis of water turbines, SAGE Publications Sage UK, London, England, 2009.

[29] H. Keck, M. Sick, Thirty years of numerical flow simulation in hydraulic turbomachines, Acta Mech 201 (2008) 211-229.

[30] Fisher RK, Seidel U, Grosse G, Gfeller W, Klinger R. A case study in resonant hydroelastic vibration: the causes of runner cracks and the solutions implemented for the Xiaolangdi hydroelectric project. In: Proceedings of the XXI IAHR symposium on hydraulic machinery and systems; 2002.

[31] M. Gagnon, A. Tahan, P. Bocher, D. Thibault, On the stochastic simulation of hydroelectric turbine blades transient response, Mech Syst Signal Process 32 (2012) 178-187.

[32] Nennemann B, Morissette JF, Chamberland-Lauzon J, Monette C, Braun O, Melot M. et al. Challenges in dynamic pressure and stress predictions at no-load operation in hydraulic turbines. In: IOP conference series: earth and environmental science, 22; 2014, p. 032055

[33] W. Wilhelm, L. Florian von, C. Philipp, K. Jiri, Dynamic stresses in a Francis model turbine at deep part load, J Phys: Conf Ser 813 (2017) 012014.

[34] Mende C, Weber W, Seidel U. Progress in load prediction for speed-no-load operation in Francis turbines. IOP conference series: earth and environmental science, 49; 2016, p. 062017

[35] M. Amabili, M.K. Kwak, Free vibrations of circular plates coupled with liquids: Revising the Lamb problem, J Fluids Struct 10 (1996) 743-761.

[36] Y. Kubota, T. Suzuki, Added mass effect on disc vibrating in fluid, Trans Jpn Soc Mech Eng C 50 (1984) 243-248.

[37] E. Askari, K.-H. Jeong, M. Amabili, Hydroelastic vibration of circular plates im mersed in a liquid-filled container with free surface, J Sound Vib 332 (2013) 3064-3085.

[38] D. Valentín, A. Presas, E. Egusquiza, C. Valero, Experimental study on the added mass and damping of a disk submerged in a partially fluid-filled tank with small
[40] T. Naik, E.K. Longmire, S.C. Mantell, Dynamic response of a cantilever in liquid near a solid wall, Sens Actuators A: Phys 102 (2003) 240-254.

[41] C.G. Rodriguez, P. Flores, F.G. Pierart, L.R. Contzen, E. Egusquiza, Capability of structural-acoustical FSI numerical model to predict natural frequencies of submerged structures with nearby rigid surfaces, Comput Fluids 64 (2012) 117-126.

[42] C.G. Rodriguez, E. Egusquiza, X. Escaler, Q.W. Liang, F. Avellan, Experimental in vestigation of added mass effects on a Francis turbine runner in still water, J Fluids Struct 22 (2006) 699-712.

[43] Q.W. Liang, C.G. Rodríguez, E. Egusquiza, X. Escaler, M. Farhat, F. Avellan, Numerical simulation of fluid added mass effect on a francis turbine runner, Comput Fluids 36 (2007) 1106-1118.

[44] Presas A, Valero C, Huang X, Egusquiza E, Farhat M, Avellan F. Analysis of the dynamic response of pump-turbine runners-Part I: Experiment. In: IOP conference series: earth and environmental science: IOP publishing; 2012, p. 052015.

[45] M. Bossio, D. Valentín, A. Presas, D.R. Martin, E. Egusquiza, C. Valero, et al., Numerical study on the influence of acoustic natural frequencies on the dynamic behaviour of submerged and confined disk-like structures, J Fluids Struct 73 (2017) 53-69.

[46] A. Presas, D. Valentin, E. Egusquiza, C. Valero, M. Egusquiza, M. Bossio, Accurate determination of the frequency response function of submerged and confined structures by using PZT-patches, Sensors 17 (2017) 660.

[47] J. Gauthier, A. Giroux, S. Etienne, F. Gosselin, A numerical method for the determination of flow-induced damping in hydroelectric turbines, J Fluids Struct 69 (2017) 341-354.

[48] Monette C, Nennemann B, Seeley C, Coutu A, Marmont H. Hydro-dynamic damping theory in flowing water. In: IOP conference series: earth and environmental science: IOP publishing; 2014, p. 032044.

[49] Gauthier J, Giroux A, Etienne S, Gosselin F. CFD evaluation of added damping due to fluid flow over a hydroelectric turbine blade. In: IOP conference series: earth and environmental science: IOP publishing; 2016, p. 072003.

[50] A. Presas, D. Valentin, E. Egusquiza, C. Valero, U. Seidel, Influence of the rotation on the natural frequencies of a submerged-confined disk in water, J Sound Vib 337 (2015) 161-180.

[51] A. Presas, E. Egusquiza, C. Valero, D. Valentin, U. Seidel, Feasibility of using PZT actuators to study the dynamic behavior of a rotating disk due to rotor-stator interaction, Sensors 14 (2014) 11919-11942.

[52] A. Presas, D. Valentin, E. Egusquiza, C. Valero, U. Seidel, On the detection of natural frequencies and mode shapes of submerged rotating disk-like structures from the casing, Mech Syst Signal Process 60 (2015) 547-570.

[53] A. Presas, D. Valentin, E. Egusquiza, C. Valero, U. Seidel, Dynamic response of a rotating disk submerged and confined. Influence of the axial gap, J Fluids Struct 62 (2016) 332-349.

[54] C. Trivedi, M.J. Cervantes, Fluid-structure interactions in Francis turbines: a perspective review, Renew Sustain Energy Rev 68 (2017) 87-101.

[55] D. Valentín, A. Presas, E. Egusquiza, C. Valero, M. Egusquiza, Experimental study of a vibrating disk submerged in a fluid-filled tank and confined with a nonrigid cover, J Vib Acoust 139 (2017), [021005-11].

[56] E. Egusquiza, D. Valentín, A. Presas, C. Valero, Overview of the experimental tests in prototype, J Phys: Conf Ser (2017)012037.

[57] Gagnon M, Tahan SA, Bocher P, Thibault D. Impact of startup scheme on Francis runner life expectancy. In: IOP conference series: earth and environmental science, 12; 2010, p. 012107.

[58] Naudascher E. Flow-induced vibrations: an engineering guide: IAHR hydraulic structures design manuals 7: Routledge; 2017.

[59] P. Dörfler, M. Sick, A. Coutu, Flow-induced pulsation and vibration in hydroelectric machinery: engineer's guidebook for planning, design and troubleshooting, Springer Science \& Business Media, 2012.

[60] He LY, Wang ZW, Kurosawa S, Nakahara Y. Resonance investigation of pump-turbine during startup process. In: IOP conference series: earth and environmental science, 22; 2014, p. 032024

[61] Seidel U, Hübner B, Löfflad J, Faigle P. Evaluation of RSI-induced stresses in Francis runners. In: IOP conference series: earth and environmental science,15; 2012, p. 052010.

[62] Zobeiri A. Investigations of time dependent flow phenomena in a turbine and a pump-turbine of francis type: rotor stator interactions and precessing vortex rope. EPFL Doctoral Thesis; 2009.

[63] Favrel A, Landry C, Müller A, Yamamoto K, Avellan F. Hydro-acoustic resonanc behavior in presence of a precessing vortex rope: observation of a lock-in phenomenon at part load Francis turbine operation. In: IOP conference series: earth and environmental science, 22; 2014, p. 032035.

[64] A. Favrel, A. Müller, C. Landry, K. Yamamoto, F. Avellan, LDV survey of cavitation and resonance effect on the precessing vortex rope dynamics in the draft tube of Francis turbines, Exp Fluids 57 (2016) 168

[65] A. Presas, D. Valentin, M. Egusquiza, C. Valero, E. Egusquiza, Sensor-based optimized control of the full load instability in large hydraulic turbines, Sensors 18 (2018) 1038

[66] D. Valentín, A. Presas, E. Egusquiza, C. Valero, M. Egusquiza, M. Bossio, Power swing generated in francis turbines by part load and overload instabilities, Energies 10 (2017) 2124

[67] Yamamoto K, Müller A, Favrel A, Landry C, Avellan F. Guide vanes embedded visualization technique for investigating Francis runner inter-blade vortices at deep part load operation. In: Proceedings of the 6th IAHR international meeting of the workgroup on cavitation and dynamic problems in hydraulic machinery and systems, Ljubljana, Slovania; 2015.

[68] Seidel U, Mende C, Hübner B, Weber W, Otto A. Dynamic loads in Francis runners and their impact on fatigue life. In: IOP conference series: earth and environmental science, 22; 2014, p. 032054.

[69] M. Amabili, Effect of finite fluid depth on the hydroelastic vibration of circular and annular plate, J Sound Vib 193 (1996) 909-925. 
[70] O. De La Torre, X. Escaler, E. Egusquiza, M. Farhat, Experimental investigation of added mass effects on a hydrofoil under cavitation conditions, J Fluids Struct 39 (2013) 173-187.

[71] A. Ducoin, B. Huang, Y.L. Young, Numerical modeling of unsteady cavitating flows around a stationary hydrofoil, Int J Rotating Mach 2012 (2012) 1-17.

[72] A. Ducoin, J. André Astolfi, J.-F. Sigrist, An experimental analysis of fluid structure interaction on a flexible hydrofoil in various flow regimes including cavitating flow, Eur J Mech - B/Fluids 36 (2012) 63-74.

[73] A. Lelong, P. Guiffant, J.A. Astolfi, An experimental analysis of the structural response of flexible lightweight hydrofoils in cavitating flow, J Fluids Eng 140 (2018) 021116.

[74] X. Liu, Y. Luo, A. Presas, Z. Wang, L. Zhou, Cavitation effects on the structural resonance of hydraulic turbines: failure analysis in a real francis turbine runner, Energies 11 (2018) 2320.

[75] Blevins RD. Flow-induced vibration; 1990.

[76] C. Trivedi, A review on fluid structure interaction in hydraulic turbines: a focus on hydrodynamic damping, Eng Fail Anal 77 (2017) 1-22.

[77] Huang X, Chamberland-Lauzon J, Oram C, Klopfer A, Ruchonnet N. Fatigue analyses of the prototype Francis runners based on site measurements and simulations. In: IOP conference series: earth and environmental science, 22; 2014, p. 012014.

[78] Storli PT, Nielsen TK. Dynamic load on a Francis turbine runner from simulations based on measurements. In: IOP conference series: earth and environmental science, 22; 2014, p. 032056.

[79] R. Xiao, Z. Wang, Y. Luo, Dynamic stresses in a Francis turbine runner based on fluid-structure interaction analysis, Tsinghua Sci Technol 13 (2008) 587-592.

[80] Zhu WR, Xiao RF, Yang W, Liu J, Wang FJ. Study on stress characteristics of Francis hydraulic turbine runner based on two-way FSI. In: IOP conference series: earth and environmental science, 15; 2012, p. 052016.

[81] Huang X, Oram C, Sick M. Static and dynamic stress analyses of the prototype high head Francis runner based on site measurement. In: IOP conference series: earth and environmental science, 22; 2014, p. 032052

[82] Monette C, Marmont H, Chamberland-Lauzon J, Skagerstrand A, Coutu A, Carlev J. Cost of enlarged operating zone for an existing Francis runner. In: IOP conference series: earth and environmental science, 49; 2016, p. 072018.

[83] Löfflad J, Eissner M, Graf B. Strain gauge measurements of rotating parts with telemetry. In: Proceedings of the 9th international conference on hydraulic efficiency measurements Trondheim, Norway; 2012.

[84] Arpin-Pont J, Gagnon M, Tahan SA, Coutu A, Thibault D. Strain gauge measurement uncertainties on hydraulic turbine runner blade. In: IOP conference series: earth and environmental science, 15; 2012, p. 062042.

[85] Gagnon M, Nicolle J, Morissette JF, Lawrence M. A look at Francis runner blades response during transients. In: IOP conference series: earth and environmental science, 49; 2016, p. 052005.

[86] C. Trivedi, B. Gandhi, C.J. Michel, Effect of transients on Francis turbine runner life: a review, J Hydraul Res 51 (2013) 121-132.

[87] Coutu A, Monette C, Nennemann B, Chamberland-Lauzon J. Specific speed effec on Francis Runner reliability under various operating conditions. In: Ávila SM, editor. XXXVII Iberian Latin-American congress on computational methods in engineering. Brasilia, Brazil; 2016.

[88] Coutu A, Monette C, Gagnon M. Life assessment of francis runners using strain gage site measurements. Waterpower XV, Chattanooga, TN; 2007.

[89] J.H. Gummer, S. Etter, Cracking of Francis runners during transient operation, Int J Hydropower Dams 15 (2008) 81-85.

[90] Diagne I, Gagnon M, Tahan A. Modeling the dynamic behavior of turbine runner blades during transients using indirect measurements. In: IOP conference series: earth and environmental science, 49; 2016, p. 072014

[91] Nicolle J, Giroux AM, Morissette JF. CFD configurations for hydraulic turbine startup. In: IOP conference series: earth and environmental science, 22; 2014, p. 032021.

[92] Morissette JF, Chamberland-Lauzon J, Nennemann B, Monette C, Giroux AM Coutu A. et al. Stress predictions in a Francis turbine at no-load operating regime. In: IOP conference series: earth and environmental cience, 49; 2016, p. 072016.

[93] Bouajila S, De Colombel T, Lowys P, Maitre T. Hydraulic phenomena frequency signature of francis turbines operating in part load conditions. In: IOP conference series: earth and environmental science: IOP publishing; 2016, p. 082001.

[94] Coutu A, Akgun E, Marier S. Grid stability and effect of flexible operation on francis runners. In: Proceedings of the 10th ICOLD european club international symposium: dams and HEPPs for sustainable development, Antalya, Turkey; 2016.

[95] C. Trivedi, O.G. Dahlhaug, Interaction between trailing edge wake and vortex rings in a Francis turbine at runaway condition: compressible large eddy simulation, Phys Fluids 30 (2018) 075101.

[96] C. Trivedi, M.J. Cervantes, B.K. Gandhi, O.G. Dahlhaug, Transient pressure measurements on a high head model francis turbine during emergency shutdown, total load rejection, and runaway, J Fluids Eng 136 (2014), [121107-18].

[97] C. Trivedi, Compressible large eddy simulation of a francis turbine during speed-no-load: rotor stator interaction and inception of a vortical flow, J Eng Gas Turbines Power 140 (2018), [112601-18].

[98] A. Favrel, A. Müller, C. Landry, K. Yamamoto, F. Avellan, Study of the vortex-induced pressure excitation source in a Francis turbine draft tube by particle image velocimetry, Exp Fluids 56 (2015) 215.

[99] Avellan F. Flow investigation in a Francis draft tube: the FLINDT project. In: Proceedings of the 20th IAHR symposium on hydraulic machinery and systems; 2000.
[100] F. Duparchy, A. Favrel, P.Y. Lowys, C. Landry, A. Müller, K. Yamamoto, et al., Analysis of the part load helical vortex rope of a Francis turbine using on-board sensors, J Phys: Conf Ser 656 (2015) 012061.

[101] F. Duparchy, J. Brammer, M. Thibaud, A. Favrel, P. Lowys, F. Avellan, Mechanical impact of dynamic phenomena in Francis turbines at off design conditions, $J$ Phys: Conf Ser (2017)012035.

[102] Guillaume R, Deniau JL, Scolaro D, Colombet C. Influence of the rotor-stator in teraction on the dynamic stresses of Francis runners. In: IOP conference series: earth and environmental science, 15; 2012, p. 052011.

[103] A. Presas, D. Valentin, E. Egusquiza, C. Valero, Detection and analysis of part load and full load instabilities in a real Francis turbine prototype, J Phys: Conf Ser (2017)012038.

[104] L. Jintao, L. Shuhong, S. Yuekun, W. Yulin, W. Leqin, Three dimensional flow simulation of load rejection of a prototype pump-turbine, Eng Comput 29 (2012) 417-426.

[105] Chirkov D, Avdyushenko A, Panov L, Bannikov D, Cherny S, Skorospelov V. et al. CFD simulation of pressure and discharge surge in Francis turbine at off-design conditions. In: IOP conference series: earth and environmental science, 15; 2012, p. 032038.

[106] Cherny S, Chirkov D, Bannikov D, Lapin V, Skorospelov V, Eshkunova I. et al. 3D numerical simulation of transient processes in hydraulic turbines. In: IOP conference series: earth and environmental science, 12; 2010, p. 012071.

[107] M. Poirier, M. Gagnon, A. Tahan, A. Coutu, J. Chamberland-lauzon, Extrapolation of dynamic load behaviour on hydroelectric turbine blades with cyclostationary modelling, Mech Syst Signal Process 82 (2017) 193-205.

[108] T.L. Wahl Discussion of "Despiking acoustic doppler velocimeter data" by Derek G. Goring and Vladimir I. Nikora J Hydraulic Eng 129 (2003) 484-487

[109] L. Ljung, System identification. Signal analysis and prediction, Springer, 1998163-173.

[110] Thévenaz L, Niklès M, Fellay A, Facchini M, Robert PA. Truly distributed strain and temperature sensing using embedded optical fibers. Smart structures and materials 1998: sensory phenomena and measurement instrumentation for smart structures and materials; 1998,3330 , p. 301-14.

[111] M. Froggatt, J. Moore, High-spatial-resolution distributed strain measurement in optical fiber with Rayleigh scatter, Appl Opt 37 (1998) 1735-1740.

[112] R. Bernini, A. Minardo, L. Zeni, Dynamic strain measurement in optical fibers by stimulated Brillouin scattering, Opt Lett 34 (2009) 2613-2615.

[113] B. Lee, Review of the present status of optical fiber sensors, Opt Fiber Techno 9 (2003) 57-79.

[114] Kreuzer M. Strain measurement with fiber Bragg grating sensors. HBM, Darmstadt, S2338-10 e; 2006.

[115] A. Minardo, A. Coscetta, S. Pirozzi, R. Bernini, L. Zeni, Experimental modal analy sis of an aluminum rectangular plate by use of the slope-assisted BOTDA method, Smart Mater Struct (2013) 22.

[116] J. Klemenc, M. Fajdiga, Predicting smoothed loading spectra using a combined multilayer perceptron neural network, Int J Fatigue 28 (2006) 777-791.

[117] J. Klemenc, M. Fajdiga, A neural network approach to the simulation of load histories by considering the influence of a sequence of rainflow load cycles, Int $\mathrm{J}$ Fatigue 24 (2002) 1109-1125.

[118] P. Johannesson, Extrapolation of load histories and spectra, Fatigue Fract Eng Mater Struct 29 (2006) 209-217.

[119] P. Johannesson, J.-J. Thomas, Extrapolation of rainflow matrices, Extremes 4 (2001) 241-262.

[120] W.A. Gardner, A. Napolitano, L. Paura, Cyclostationarity: half a century of research, Signal Process 86 (2006) 639-697.

[121] Wang XF, Li HL, Zhu FW. The calculation of fluid-structure interaction and fatigue analysis for Francis turbine runner. In: IOP conference series: earth and environmental science, 15; 2012, p. 052014.

[122] C. Amzallag, J. Gerey, J. Robert, J. Bahuaud, Standardization of the rainflow counting method for fatigue analysis, Int J Fatigue 16 (1994) 287-293.

[123] Y.-L. Lee, Fatigue testing and analysis: theory and practice, Butterworth-Heinemann, 2005.

[124] Z. Birnbaum, S.C. Saunders, A probabilistic interpretation of miner's rule, SIAM J Appl Math 16 (1968) 637-652.

[125] Gagnon M, Tahan SA, Bocher P, Thibault D. The role of high cycle fatigue (HCF) onset in Francis runner reliability. IOP conference series: earth and environmental science, 15; 2012, p. 022005

[126] M. Gagnon, A. Tahan, P. Bocher, D. Thibault, A probabilistic model for the onse of high cycle fatigue (HCF) crack propagation: application to hydroelectric turbine runner, Int J Fatigue 47 (2013) 300-307.

[127] M. Gagnon, A. Tahan, P. Bocher, D. Thibault, On the fatigue reliability of hydroelectric Francis runners, Procedia Eng 66 (2013) 565-574.

[128] D. Thibault, M. Gagnon, S. Godin, The effect of materials properties on the reliability of hydraulic turbine runners, Int J Fluid Mach Syst 8 (2015) 254-263.

[129] M. Gagnon, A. Tahan, P. Bocher, D. Thibault, Influence of load spectrum assumptions on the expected reliability of hydroelectric turbines: a case study, Struct Saf 50 (2014) 1-8.

[130] Kitagawa H, Takahashi S. Applicability of fracture mechanics to very small cracks or the cracks in the early stage. In: Proceedings of the second international conference on mechanical behavior of materials ASM, Metals Park, Ohio; 1976, 627-6311976.

[131] M. El Haddad, T. Topper, K. Smith, Prediction of non propagating cracks, Eng Fract Mech 11 (1979) 573-584. 